\title{
Heating Tests of AGR-2 Compact 6-4-1 Loose Kernels and AGR-3/4 Compacts 3-2 and 10-4
}

John D. Stempien

The INL is a

U.S. Department of Energy

National Laboratory

operated by

Battelle Energy Alliance

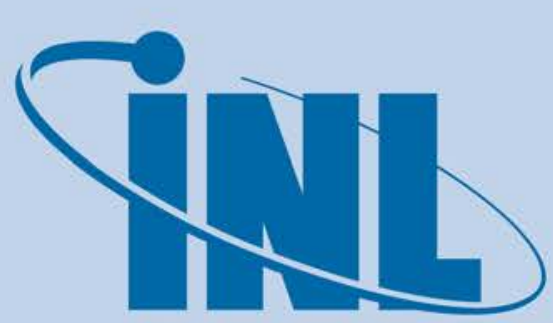

January 2018

Idaho National Laboratory

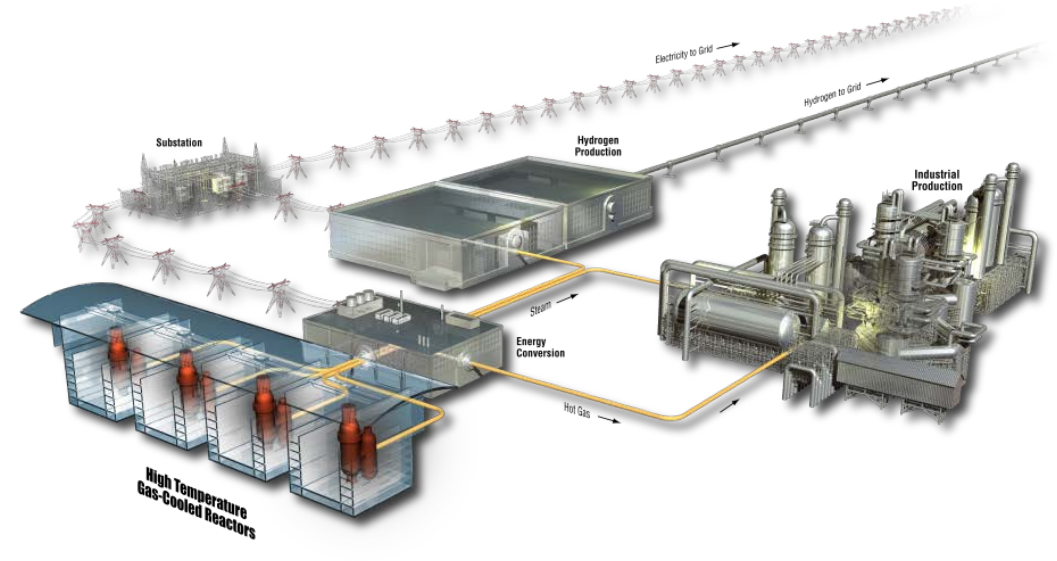




\section{DISCLAIMER}

This information was prepared as an account of work sponsored by an agency of the U.S. Government. Neither the U.S. Government nor any agency thereof, nor any of their employees, makes any warranty, expressed or implied, or assumes any legal liability or responsibility for the accuracy, completeness, or usefulness, of any information, apparatus, product, or process disclosed, or represents that its use would not infringe privately owned rights. References herein to any specific commercial product, process, or service by trade name, trade mark, manufacturer, or otherwise, does not necessarily constitute or imply its endorsement, recommendation, or favoring by the U.S. Government or any agency thereof. The views and opinions of authors expressed herein do not necessarily state or reflect those of the U.S. Government or any agency thereof. 


\title{
Heating Tests of AGR-2 Compact 6-4-1 Loose Kernels and AGR-3/4 Compacts 3-2 and 10-4
}

\author{
John D. Stempien
}

January 2018

\begin{abstract}
Idaho National Laboratory
INL ART TDO Program

Idaho Falls, Idaho 83415
\end{abstract}

http://www.inl.gov

Prepared for the

U.S. Department of Energy

Office of Nuclear Energy

Under DOE Idaho Operations Office

Contract DE-AC07-05ID14517 

INL ART TDO Program

\section{Heating Tests of AGR-2 Compact 6-4-1 Loose Kernels and AGR-3/4 Compacts 3-2 and 10-4}

INL/EXT-18-44443

January 2018

Author:
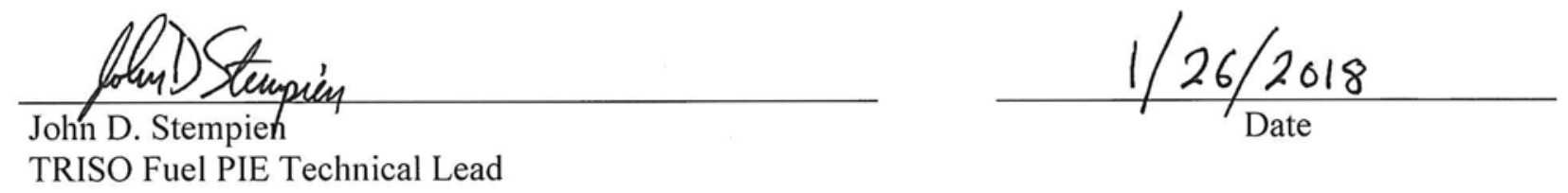

Approved by:

Paul A. Demkowciz
Director AGR Fuels

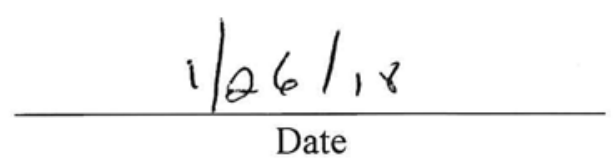

\section{Director AGR Fuels}

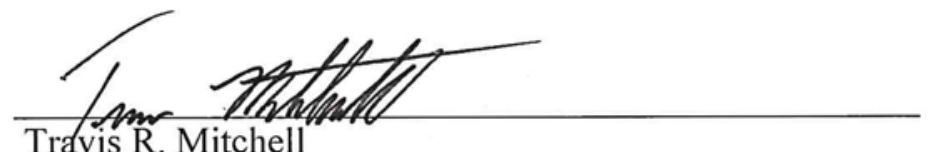

Project Manager
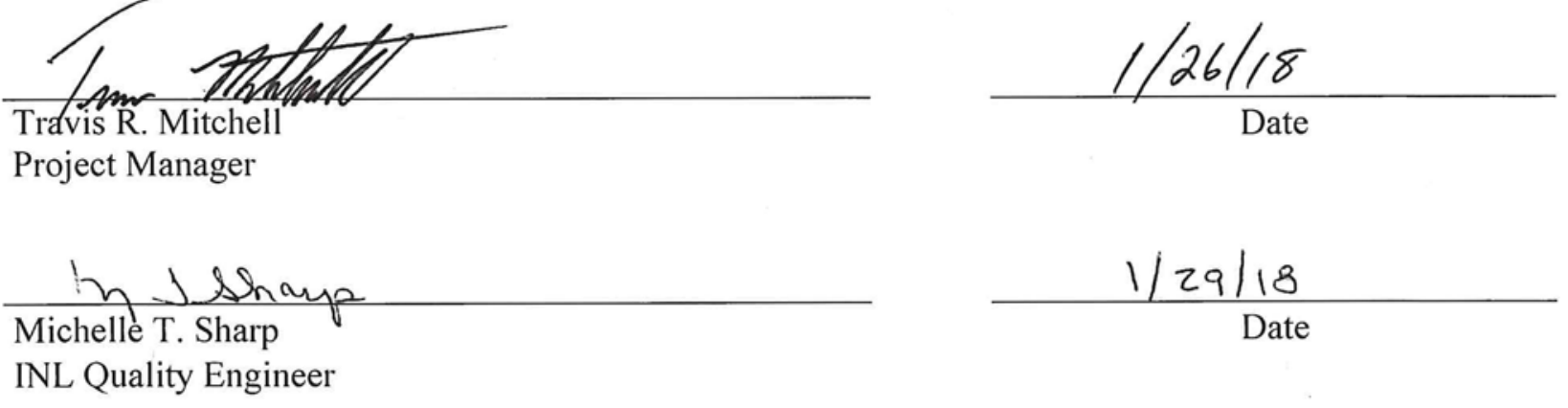



\section{REVISION LOG}

\begin{tabular}{|c|c|c|l|}
\hline Rev. & Date & Affected Pages & \multicolumn{1}{c|}{ Revision Description } \\
\hline 0 & $1 / 29 / 2018$ & All & New document. \\
\hline & & & \\
\hline & & & \\
\hline & & & \\
\hline & & & \\
\hline & & & \\
\hline & & & \\
\hline & & & \\
\hline & & & \\
\hline & & & \\
\hline & & & \\
\hline & & & \\
\hline & & & \\
\hline & & & \\
\hline
\end{tabular}





\begin{abstract}
Three heating tests in the Fuel Accident Condition Simulator (FACS) have been completed, and some preliminary results are available. Two AGR-3/4 compacts were heated in two separate tests. The test of AGR-3/4 Compact 3-2 featured a 330-hour hold at $1600^{\circ} \mathrm{C}$ and a 48 hour hold at $1700^{\circ} \mathrm{C}$. AGR-3/4 Compact 10-4 was heated for 300 hours at $1400^{\circ} \mathrm{C}$. In both tests, the fission gas Kr-85 was collected, and condensable fission product (Ag-110m, Cs-134/137, Eu-154/155, Sb-125, etc.) releases were measured via exchanges of FACS furnace condensation plates. In each of these tests, less than one particle inventory of Kr-85 and Cs-134 was measured. This indicates that no driver fuel particles failed, and that the 20 designed-to-fail (DTF) particles in each compact made only small contributions to measured releases during heating tests. It is possible that the DTF particles did not retain much of their inventory following the initial irradiation in ATR (prior to heating testing). Further post-irradiation examinations of these compacts will be performed to confirm or deny these conclusions. In addition to the two AGR-3/4 compacts, two groups of AGR-2 particles were reirradiated in the Neutron Radiography reactor (NRAD). The first group was heated in the FACS furnace to $300^{\circ} \mathrm{C}$; however, the test was aborted prior to reaching the intended $1600^{\circ} \mathrm{C}$ test temperature. The second test heated four reirradiated particles for a total of approximately 24 hours, completing approximately 15 hours at $1600^{\circ} \mathrm{C}$. Releases measured during this FACS test were compared to the particle inventories measured after reirradiation but before the heating test.
\end{abstract}




\section{ACKNOWLEDGEMENTS}

Hot Fuel Examination Facility (HFEF) process engineer Cad Christensen is recognized for leading FACS furnace operations and maintenance. Edward Reber, $\mathrm{PhD}$, is recognized for gamma counting of the particles, condensation plates, and fission gases in the FACS Fission Gas Monitoring System. 


\section{CONTENTS}

ABSTRACT. vii

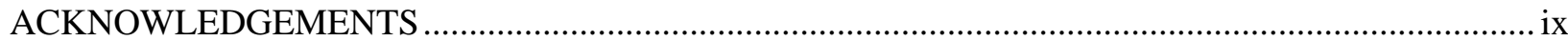

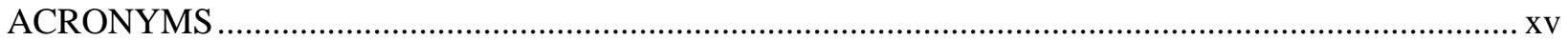

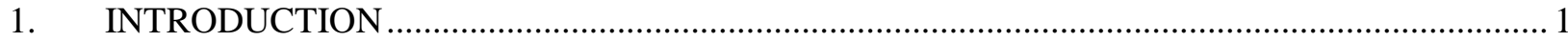

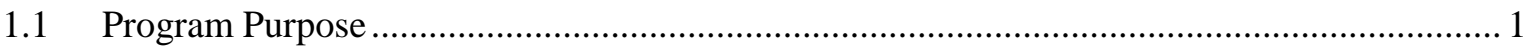

1.2 Introduction to AGR Program Irradiations ........................................................................ 1

I.3 Introduction to Post-irradiation Heating Testing ............................................................... 1

2. AGR-2 COMPACT 6-4-1 PARTICLE PREPARATION, REIRRADIATION, AND

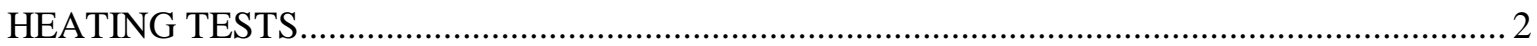

2.1 Compact Description and Irradiation History ........................................................................ 2

2.2 Particle Selection and Preparation .............................................................................. 2

2.3 Particle Gamma Counting and Reirradiation .................................................................. 5

2.4 First Reirradiation and Terminated Heating Test.............................................................. 8

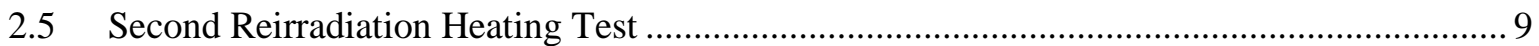

2.5.1 Temperature program and condensation plate exchanges.......................................... 9

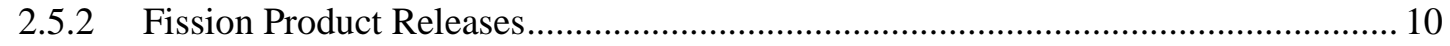

3. AGR-3/4 COMPACT 3-2 AND 10-4 HEATING TESTS …................................................... 15

3.1 Compact Fabrication and Irradiation Properties ................................................................ 15

3.2 AGR-3/4 Compact 3-2 1600 ${ }^{\circ} \mathrm{C}$ Heating Test ........................................................... 18

3.2.1 Temperature program and condensation plate exchanges........................................ 18

3.2.2 Measured Fission Product Releases ................................................................... 19

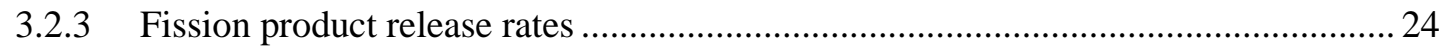

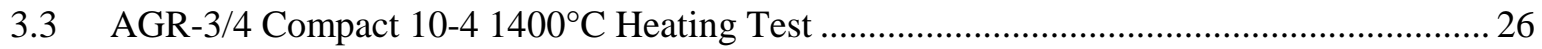

3.3.1 Temperature program and condensation plate exchanges......................................... 26

3.3.2 Measured Fission Product Releases .................................................................... 27

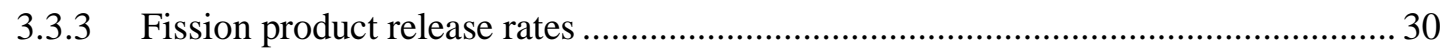

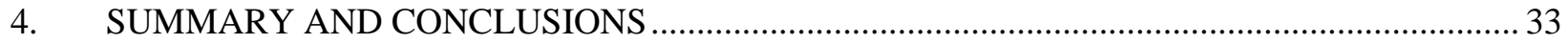

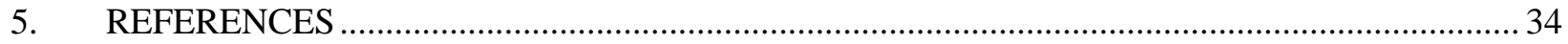

FIGURES

Figure 1. Images of crushed AGR-2 Compact 6-4-1 Group 1 particles. Each particle was imaged in an individual v-vial. Particle numbers correspond to particle IDs in Table 2......................... 4

Figure 2. Group 2 particles after cracking to remove TRISO coatings. Kernels are held on the end of a vacuum needle for imaging. Particle numbers correspond to particle IDs in Table 3. 
Figure 3. Individual alumina (ceramic) cups and graphite holders (containers) hold one particle each during reirradiation and FACS testing. The aluminum reirradiation container (capsule) holds four graphite containers at a time.

Figure 4. Planned temperature program, actual temperature, and planned condensation-plate change schedule. Test was terminated after 3.65 hours.

Figure 5. Planned temperature program and condensation plate change schedule from (Stempien 2017b).

Figure 6. Actual furnace temperature and temperature and time of condensation plate changes. Test was stopped after the first 8.8 hours, restarted, and finally stopped early after a total of 19.7 hours (approximately 10 hours at $1600^{\circ} \mathrm{C}$ ).

Figure 7. Total measured activities of condensable fission products on condensation plates and of noble-gas fission products in the FGMS as a function of test time. All activities are reported at the reference time of 9/7/2017 at 8:00 AM.

Figure 8. Ratio of the cumulative condensation-plate activity versus time to the total activity measured in all four particles after NRAD/before FACS. Values of 1.0 indicate complete release.

Figure 9. Activities of noble fission gases Kr-85 and Xe-133 measured in the FGMS during heating of group 2 cracked fuel particles/bare kernels. Activities reported at reference time of 9/7/2017 at 8:00 AM. Kr-85 activity was decay-corrected to EOI+1 day and compared to the activity in three particles predicted by physics calculations from (Sterbentz 2014).

Figure 10. Image of AGR-3/4 fuel compact (left) and x-ray cross section (right) (Hunn, Trammell, and Montgomery 2011). DTF particles are highlighted with red dots in the $\mathrm{x}$-ray at right.

Figure 11. Calculated fast fluence and TAVA temperature for each of the four compacts in each of the twelve AGR-3/4 capsules. Fluences and temperatures from (Hawkes 2016) and (Sterbentz 2015), respectively.

Figure 12. Furnace temperature and time and temperature of condensation plate exchanges for the AGR-3/4 Compact 3-2 heating test.

Figure 13. Total compact fractions of fission products measured from condensation plates from the heating test of Compact 3-2. FACS furnace temperature is also plotted along with the compact fraction equivalent to one particle inventory $(5.29 \mathrm{E}-4)$.

Figure 14. Cs-134 cumulative releases versus time.

Figure 15. Eu-154 cumulative releases versus time............................................................................... 23

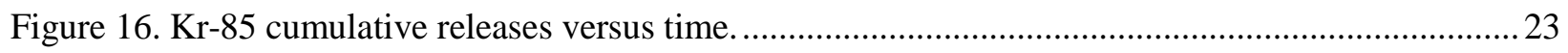

Figure 17. Summary of condensable fission-product release rates.......................................................... 25

Figure 18. Kr-85 cumulative releases and trend lines giving average release rates over the test period at $1600^{\circ} \mathrm{C}$ and including start-up to 334 hours.

Figure 19. $\mathrm{Kr}-85$ cumulative releases and trend lines giving release rates $\left(\mathrm{hr}^{-1}\right)$ during the $1700^{\circ} \mathrm{C}$ period of the test. 26

Figure 20. Temperature program and actual time and temperature of condensation-plate exchanges for the AGR-3/4 Compact 10-4 heating test. 
Figure 21. Total compact fractions of fission products measured from condensation plates from the heating test of AGR-3/4 Compact 10-4. FACS furnace temperature is also plotted along with the compact fraction equivalent to one particle inventory $(5.29 \mathrm{E}-4)$.

Figure 22. Summary of condensable fission-product release rates from $1400^{\circ} \mathrm{C}$ testing of AGR3/4 Compact 10-4.

Figure 23. Kr-85 cumulative releases versus time with trend line fit to all Kr-85 data points.................. 32

Figure 24. Kr-85 cumulative releases and trend lines giving average release rates over the test.

\section{TABLES}

Table 1. Identification and irradiation conditions for AGR-2 Compact 6-4-1... 2

Table 2. First group of four AGR-2 Compact 6-4-1 particles for re-irradiation heating tests with selected results from gamma counting each particle. Particles were crushed prior to reirradiation heating testing. 3

Table 3. Second group of four AGR-2 Compact 6-4-1 particles for re-irradiation heating tests with selected results from gamma counting each particle. Particles were cracked to remove TRISO coatings without crushing the kernel prior to reirradiation heating testing. Diameters of the cracked particles were estimated from images in Figure 2.

Table 4. Activities of select isotopes in Group 2 particles after DLBL of AGR-2 Compact 6-4-1 and after particle cracking and ratios of pre- to post-cracking activities are listed. (Ce/Pr-144, Eu-155, and Ru/Rh-106 were also measured, but are not shown below.) All activities and ratios are prior to reirradiation and heating and are referenced to 9/7/2017 at 8:00 AM.

Table 5. Activities of select isotopes in Group 2 particles after reirradiation in NRAD. (Ce/Pr144, Eu-155, and Ru/Rh-106 were also measured, but are not shown below.) All activities are referenced to 9/7/2017 at 8:00 AM. Ratio of post-NRAD to pre-NRAD gamma activities.

Table 6. FACS furnace condensation plate collection efficiencies at $1600^{\circ} \mathrm{C}$

Table 7. Post-FACS test activities of particles, graphite holders, and condensation plates. All activities are referenced to 9/7/2017 8:00 AM. Ratios comparing measured activities are listed. 13

Table 8. Selected fuel-fabrication and irradiation properties for Compact 3-2. 17

Table 9. Selected fuel-fabrication and irradiation properties for Compact 10-4. 18

Table 10. AGR-3/4 DTF particle failure count in each irradiation capsule. Table from (Collin 2015b) and (Scates 2015). 18

Table 11. Total fission-product release summary for Compact 3-2 ....................................................... 23

Table 12. Summary of total fission product release from AGR-3/4 Compact 10-4. 30 


\section{ACRONYMS}

AGR Advanced Gas Reactor

ART Advanced Reactor Technologies

ATR Advanced Test Reactor

DLBL deconsolidation leach-burn-leach

DTF designed-to-fail

EOI end-of-irradiation

ESA experimental safety analysis

FACS Fuel Accident Condition Simulator

FGMS Fission Gas Monitoring System

FIMA fissions per initial heavy metal atom

HFEF Hot Fuel Examination Facility

HOG HFEF Out-of-cell Gamma

HTGR High Temperature Gas-cooled Reactor

INL Idaho National Laboratory

IPyC inner pyrolytic carbon

LBL leach-burn-leach

NRAD Neutron Radiography reactor

OPyC outer pyrolytic carbon

ORNL Oak Ridge National Laboratory

PIE post-irradiation examination

SiC silicon carbide

TA time-averaged

TAVA time-averaged volume-averaged

TRISO tristructural isotropic

UCO uranium oxycarbide 


\title{
Heating Tests of AGR-2 Compact 6-4-1 Loose Kernels and AGR-3/4 Compacts 3-2 and 10-4
}

\author{
1. INTRODUCTION \\ 1.1 Program Purpose
}

The Advanced Gas Reactor (AGR) Fuel Development and Qualification Program was established to perform research and development on tristructural isotropic (TRISO)-coated particle fuel to support deployment of a high-temperature gas-cooled reactor (HTGR). The work continues as part of the Advanced Reactor Technologies (ART) TRISO Fuel Program. The overarching goal of the program is to provide a baseline fuel qualification data set to support licensing and operation of an HTGR. To achieve these goals, the program includes the elements of fuel fabrication, irradiation, post-irradiation examination (PIE) and safety/heating testing, fuel performance modeling, and fission product transport (INL 2016). Several fuel irradiation experiments have been performed at the Advanced Test Reactor (ATR) at Idaho National Laboratory (INL), and additional irradiations are planned. These experiments are intended to provide data on fuel performance under irradiation, support fuel fabrication process development, qualify fuel for operating and accident conditions, provide irradiated fuel for accident testing, and support development of fuel performance and fission product transport models.

\subsection{Introduction to AGR Program Irradiations}

The first two fuel irradiation experiments (AGR-1 and AGR-2) had similar designs, and the primary objective was to test coated-particle fuel performance over a range of irradiation temperatures and burnups. Both irradiations are complete (Collin 2015a and Collin 2014), as are the major components of AGR-1 PIE (Demkowicz et al. 2015a). This report describes the reirradiation and high-temperature testing of fuel particles deconsolidated from AGR-2 Compact 6-4-1. The AGR-2 experiment was irradiated in the B-12 position of the ATR from June 2010 to October 2013 (Collin 2014). AGR-2 PIE began in July 2014, is still in-progress, and encompasses as-irradiated analyses, reirradiations, heating testing, and other activities.

The third irradiation experiment, AGR-3/4, was designed to investigate the migration of fission products in fuel compact graphitic matrix and reactor graphite components. This report describes the high-temperature testing of two AGR-3/4 compacts (Compacts 3-2 and 10-4). The AGR-3/4 experiment was irradiated in the northeast flux trap of ATR, from December 2011 to April 2014 (Collin 2015b). The experiment consisted of fuel compacts containing TRISO-coated driver-fuel particles (similar to AGR-1 baseline fuel [Collin 2015b]) and designed-to-fail (DTF) particles that are designed to release fission products during irradiation, which will migrate through the surrounding cylindrical rings of graphitic matrix and nuclear-grade graphite. Evaluation of the fission product distribution in these rings and fuel compacts following irradiation is a critical component of the experiment, providing data that will support refinement of fission product transport models.

\subsection{Introduction to Post-irradiation Heating Testing}

In addition to studying fuel performance (fuel fission product retention and TRISO coating stability) under normal reactor conditions, the AGR program utilizes post-irradiation heating tests to observe fuel performance at high temperatures characteristic of accidents and to study fission product transport within the fuel kernel, TRISO coatings, and graphitic materials. Two groups of loose particles obtained from the deconsolidation of AGR-2 Compact 6-4-1 were reirradiated in the Neutron Radiography Reactor (NRAD) and subsequently heated in the Fuel Accident Condition Simulator (FACS) furnace. AGR-3/4 Compact 3-2 and Compact 10-4 were separately heated in the FACS furnace at temperatures of $1600^{\circ} \mathrm{C}$ (with a short period at $1700^{\circ} \mathrm{C}$ ) and $1400^{\circ} \mathrm{C}$, respectively. 
The FACS furnace is located at Window 6M in the main hot cell at the Hot Fuel Examination Facility (HFEF). The furnace is capable of temperatures in excess of $1800^{\circ} \mathrm{C}$. Samples are held by tantalum sample holders inside a tantalum flow tube (main furnace chamber). A helium sweep gas at a total flow rate of $1 \mathrm{~L} / \mathrm{min}$ passed through furnace. Other flow rates are possible, but $1 \mathrm{~L} / \mathrm{min}$ is the standard flow rate used for the tests described here. The helium sweep gas carries any fission gases that may be released from the irradiated fuel samples to the fission gas monitoring system (FGMS), which collects and counts fission gases $\mathrm{Kr}-85$ and Xe-133 throughout the test. A water-cooled cold finger at the top of the FACS furnace holds condensation plates, which collect condensable fission products (e.g., Ag, Cs, Eu, Sr, etc.). The condensation plates are swapped at various points during the test, and post-test analyses are used to quantify the activity of fission products on each plate. Additional information on the FACS furnace is available in (Demkowicz et al. 2012, and Demkowicz et al. 2015b).

\section{AGR-2 COMPACT 6-4-1 PARTICLE PREPARATION, REIRRADIATION, AND HEATING TESTS \\ 2.1 Compact Description and Irradiation History}

Compact 6-4-1 was irradiated in Capsule 6, Level 4, Stack 1 (facing the ATR core) in the B-12 position of ATR at INL (Collin 2014). Approximately 3176 TRISO-coated fuel particles were in the compact. As-manufactured fuel properties are summarized in Appendix A of (Collin 2014). Each fuel particle has a central kernel comprised of a mixture of uranium oxide and uranium carbide, and this mixture is often termed uranium oxycarbide (UCO). Table 1 lists the irradiation conditions and compact IDs for AGR-2 Compact 6-4-1.

Table 1. Identification and irradiation conditions for AGR-2 Compact 6-4-1.

\begin{tabular}{|l|l|l|l|l|}
\hline Compact ID & Fabrication ID & $\begin{array}{l}\text { Average Burnup } \\
(\% F I M A)^{\mathrm{c}}\end{array}$ & $\begin{array}{l}\text { Average Fast Fluence } \\
\times 10^{25}\left(\mathrm{n} / \mathrm{m}^{2}\right)^{\mathrm{c}}\end{array}$ & $\begin{array}{l}\text { Irradiation } \\
\text { Temperature }\left({ }^{\circ} \mathrm{C}\right)^{\mathrm{d}}\end{array}$ \\
\hline $6-4-1$ & LEU09-OP2-Z016 & 9.24 & 2.20 & 1018 \\
\hline
\end{tabular}

a. The X-Y-Z naming convention denotes the location in the irradiation test train: Capsule-Level-Stack (Demkowicz 2013).

b. Compact-specific fabrication ID (Collin 2011).

c. Based on physics calculations (Sterbentz 2014).

d. Time-averaged, volume-averaged temperature based on thermal calculations (Hawkes 2014).

\subsection{Particle Selection and Preparation}

Loose TRISO-coated fuel particles were obtained via electrolytic deconsolidation-leach-burn-leach (DLBL) of irradiated AGR-2 Compact 6-4-1. The general DLBL process is described in Appendix A of (Demkowicz et al. 2016). After DLBL, 60 particles were chosen at random, visually inspected, and gamma surveyed according to the description in Appendix B of (Demkowicz et al. 2016). The reirradiation heating tests are currently designed for four particles at a time (although up to 20 particles could be tested at a time [Laug 2017]). Two groups of four particles per group were chosen for reirradiation heating tests.

Table 2 lists the first group of four particles and selected post-DLBL gamma survey results for each particle. Table 3 lists the second group of four particles and post-DLBL gamma survey results. The Ag-110m, Cs-134, and Eu-154 measured-to-calculated (M/C) ratios listed in Table 2 and Table 3 were calculated by taking the measured activities for each isotope (M), decay-correcting them to end-ofirradiation plus one day (EOI +1$)$, and dividing by the calculated average particle inventory (C) from (Sterbentz 2014). ${ }^{a}$ The average calculated inventory for an individual Compact 6-4-1 particle is equal to

a Note that the particle $\mathrm{M} / \mathrm{C}$ ratios were not normalized (by relative Cs or Ce content) to account for particle-to-particle variations in fissile content. To compare the AGR-2 Compact 6-4-1 particle data to AGR-1, that normalization is required. 
the calculated compact inventory divided by the number of particles in a compact, 3176 . The main criterion used for selecting each group of four particles for reirradiation and heating was that they cover a range of Ag- $110 \mathrm{~m} \mathrm{M} / \mathrm{C}$ ratios. The Ag- $110 \mathrm{~m} \mathrm{M} / \mathrm{C}$ range across 60 particles was 0.34 to 1.17. For the Cs-137:Ce-144 ratio and Ru/Rh-106:Ce-144 ratios listed in Table 2 and Table 3, the measured activities were decay corrected to EOI+1, the ratios of the isotope activities were taken, and those ratios were normalized by the corresponding average ratio from all 60 measured particles from Compact 6-4-1.

Intact TRISO coatings prevent fission-product release, and fission-product gases are well retained as long as one of the three TRISO coating layers (inner pyrolytic carbon [IPyC], silicon carbide [SiC], or outer pyrolytic carbon [OPyC]) is intact. To specifically study fission-product release (and retention) from the central fuel kernels, defects must be intentionally generated in the TRISO layers. After selecting particles, defects were created prior to reirradiation using two methods. The first group of particles (listed in Table 2) was crushed in order to break the TRISO layers. Figure 1 shows images of each of the four Group 1 particles after crushing. The images were taken with each crushed particle in the bottom of individual v-vials. The crushed particles have no intact TRISO layers, and the kernels appear to have been crushed as well.

The second group of particles (listed in Table 3) was cracked to remove the TRISO layers (including the buffer layer) without crushing the underlying fuel kernel. Figure 2 shows the kernels that were recovered after cracking off the TRISO coatings from the four particles listed in Table 3 . The kernels are held on the end of a 25 gauge needle via pneumatic suction. The needle has an outer diameter of $0.5144 \mathrm{~mm}$, and using this known diameter, the diameters of the particles were estimated. The approximate diameters for each particle are listed in Table 3. An average as-fabricated kernel diameter was $425 \mu \mathrm{m}$ (Collin 2014). The estimated diameters for the cracked particles could be larger than the as-fabricated kernel diameters due to kernel swelling during irradiation or a portion of the buffer layer remaining attached to the kernel.

Table 2. First group of four AGR-2 Compact 6-4-1 particles for re-irradiation heating tests with selected results from gamma counting each particle. Particles were crushed prior to reirradiation heating testing.

\begin{tabular}{|l|l|l|l|l|l|}
\hline $\begin{array}{l}\text { Particle } \\
\mathrm{ID}^{\mathrm{a}}\end{array}$ & $\begin{array}{l}\text { Ag-110m } \\
\text { Inventory } \\
(\mathrm{M} / \mathrm{C})\end{array}$ & $\begin{array}{l}\text { Cs-134 } \\
\text { Inventory } \\
(\mathrm{M} / \mathrm{C})\end{array}$ & $\begin{array}{l}\text { Eu-154 } \\
\text { Inventory } \\
(\mathrm{M} / \mathrm{C})\end{array}$ & $\begin{array}{l}\text { Measured Activity Ratio } \\
\text { Cs-137:Ce-144 }\end{array}$ & $\begin{array}{l}\text { Measured Activity Ratio } \\
\text { Ru/Rh-106:Ce-144 }\end{array}$ \\
\hline $99953-1$ & 0.731 & 0.788 & 0.774 & 1.07 & 1.04 \\
\hline $99953-3$ & 0.341 & 0.888 & 0.766 & 0.968 & 0.963 \\
\hline $99953-26$ & 0.481 & 0.739 & 0.644 & 0.943 & 1.00 \\
\hline $99953-34$ & 0.754 & 0.877 & 0.776 & 1.01 & 0.972 \\
\hline
\end{tabular}

a. Note that particles were transferred from the Analytical Laboratory to the Hot-Fuel Examination Facility in the following container IDs: 99953-1 in container 2; 99953-3 container 1; 99953-26 in container 2a; 99953-34 container 3. 
Table 3. Second group of four AGR-2 Compact 6-4-1 particles for re-irradiation heating tests with selected results from gamma counting each particle. Particles were cracked to remove TRISO coatings without crushing the kernel prior to reirradiation heating testing. Diameters of the cracked particles were estimated from images in Figure 2.

\begin{tabular}{|l|l|l|l|l|l|l|}
\hline $\begin{array}{l}\text { Particle } \\
\text { ID }^{\text {a }}\end{array}$ & $\begin{array}{l}\text { Ag-110m } \\
\text { Inventory } \\
(\mathrm{M} / \mathrm{C})\end{array}$ & $\begin{array}{l}\text { Cs-134 } \\
\text { Inventory } \\
(\mathrm{M} / \mathrm{C})\end{array}$ & $\begin{array}{l}\text { Eu-154 } \\
\text { Inventory } \\
(\mathrm{M} / \mathrm{C})\end{array}$ & $\begin{array}{l}\text { Measured } \\
\text { Activity Ratio } \\
\text { Cs-137:Ce-144 }\end{array}$ & $\begin{array}{l}\text { Measured } \\
\text { Activity Ratio } \\
\text { Ru/Rh-106:Ce-144 }\end{array}$ & $\begin{array}{l}\text { Approximate } \\
\text { Diameter of } \\
\text { Cracked } \\
\text { Particle }(\mu \mathrm{m})\end{array}$ \\
\hline $99953-11$ & 0.868 & 0.950 & 0.866 & 1.01 & 0.984 & 499.8 \\
\hline $99953-17$ & 0.648 & 0.916 & 0.802 & 1.00 & 0.967 & 487.0 \\
\hline $99953-19$ & 0.781 & 0.815 & 0.717 & 0.965 & 0.924 & 509.0 \\
\hline $99953-39$ & 0.385 & 0.907 & 0.786 & 0.972 & 0.939 & 476.0 \\
\hline
\end{tabular}

a. $\quad$ Note that at the Hot-Fuel Examination Facility, some particles were also given the following IDs: 99953-11 = AGR324, 99953-17 = AGR325, 99953-19 = AGR327.
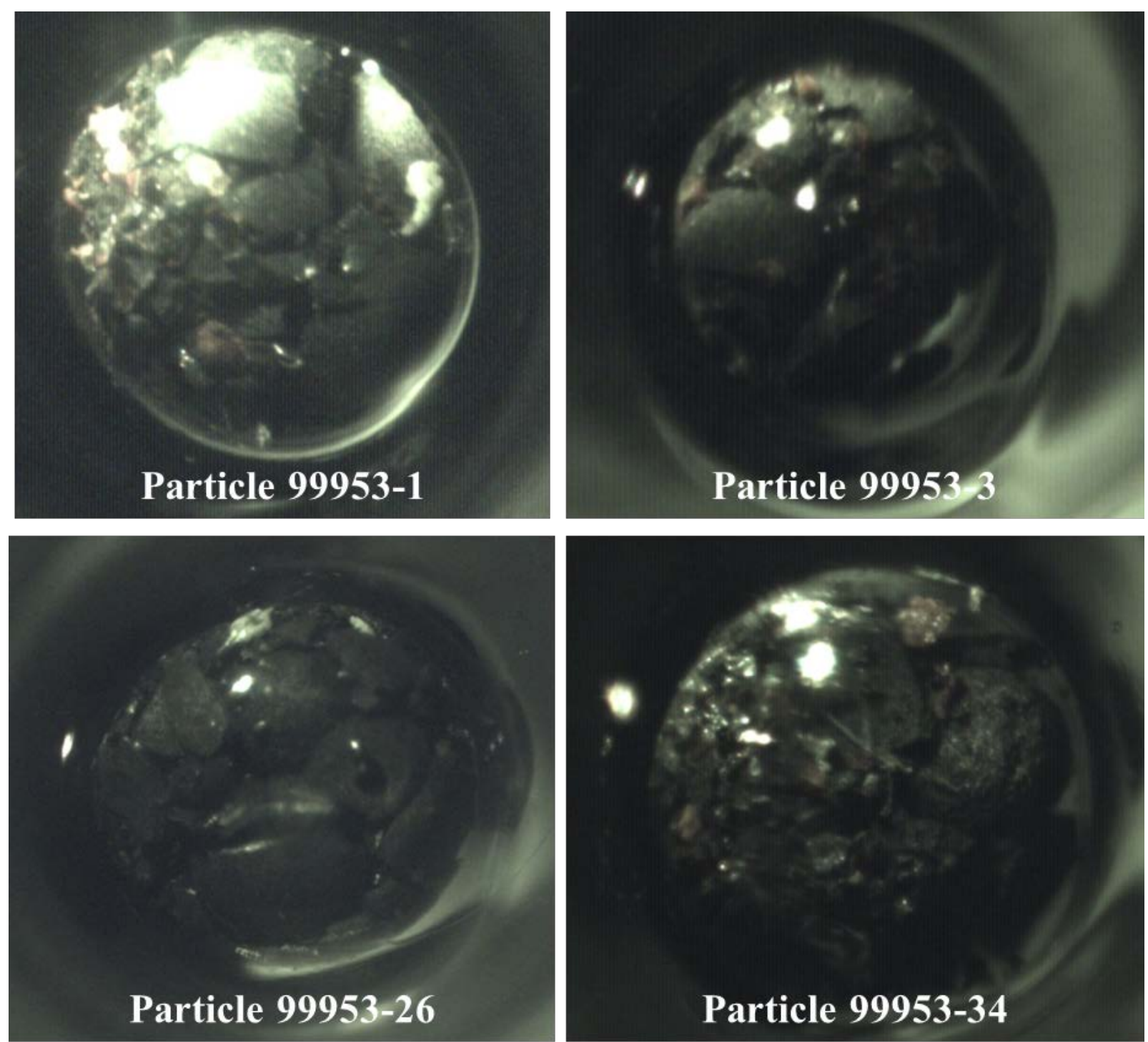

Figure 1. Images of crushed AGR-2 Compact 6-4-1 Group 1 particles. Each particle was imaged in an individual v-vial. Particle numbers correspond to particle IDs in Table 2. 

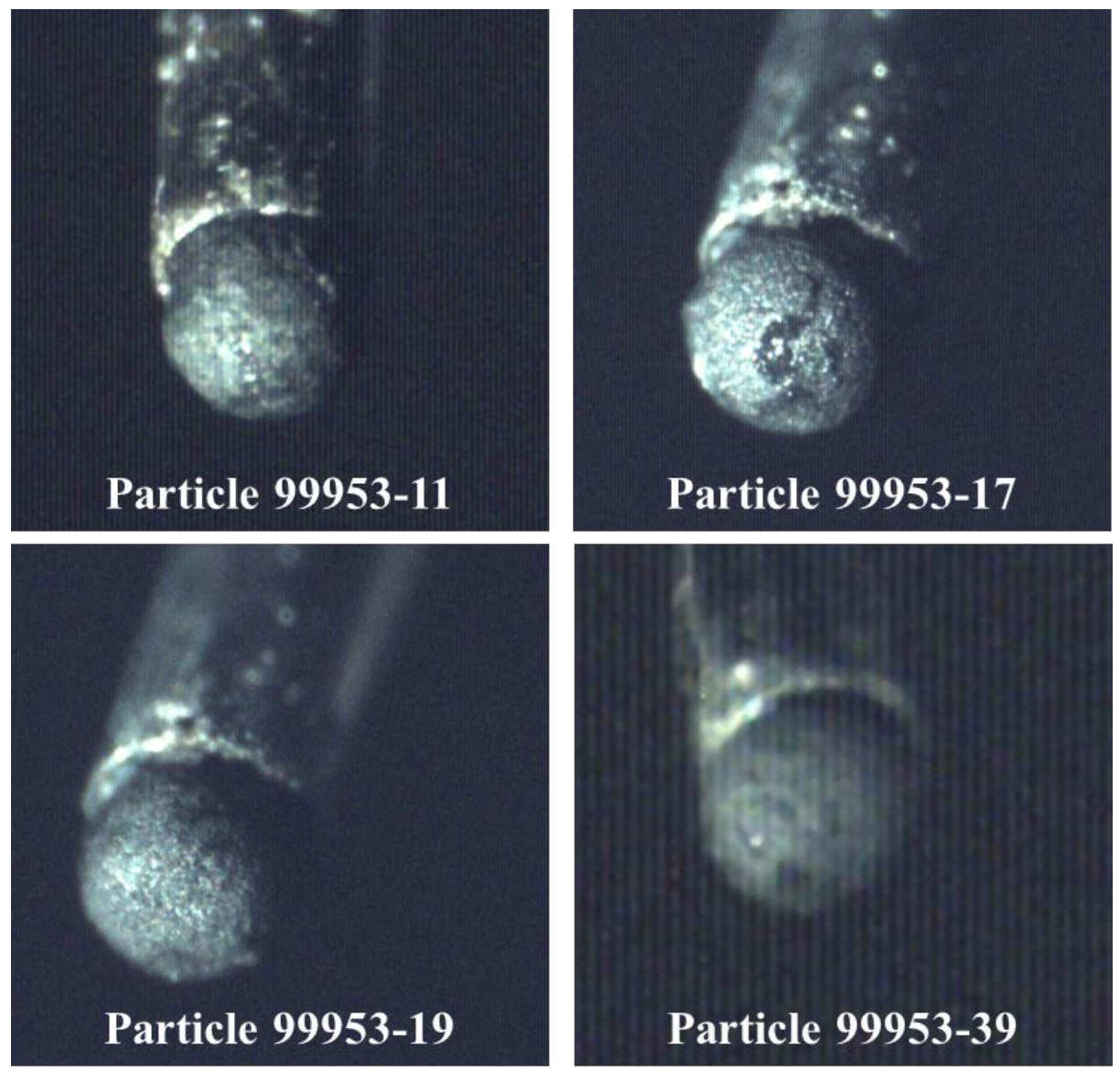

Figure 2. Group 2 particles after cracking to remove TRISO coatings. Kernels are held on the end of a vacuum needle for imaging. Particle numbers correspond to particle IDs in Table 3.

\subsection{Particle Gamma Counting and Reirradiation}

Figure 3 shows the sample holders used during the reirradiation in NRAD and subsequent heating test in the FACS furnace. After crushing (as in group 1 particles) or cracking (as in group 2 particles), the particles were loaded into individual alumina cups, which were loaded into individual graphite containers (also called graphite holders), one particle per holder. Each graphite holder, containing a single cracked or crushed particle, was gamma counted at the HFEF out-of-cell gamma (HOG) station to obtain a final fission product inventory prior to reirradiation in NRAD. The post-crushing/pre-NRAD and postNRAD/pre-FACS gamma counts of the group 1 particles are still being analyzed and were given a lower priority due to the early termination of the FACS testing of the group 1 particles (discussed in Section 2.4). Table 4 lists the post-DLBL/pre-cracking and post-cracking/pre-NRAD gamma activities for the second group of particles used in the second reirradiation heating test. (Section 2.2 described the cracking process for these particles.) Table 4 also compares these two groups of activities by taking the ratio of the post-cracking/pre-NRAD activities and the post-DLBL/pre-cracking activities. For most isotopes measured in particles 99953-11, 99953-17, and 99953-39, the ratio is greater than 0.9, indicating that the majority of the activity measured in the particle after DLBL (prior to cracking) was retained in the particle after cracking and loading into the graphite holders. This also indicates that little or no kernel material from these particles was lost through handling/cracking prior to NRAD reirradiation. For particle 99953-19, however, the ratios are low, near 4E-3. This indicates that the kernel from particle 99953-19 was lost between the cracking process and the start of the NRAD reirradiation. It is likely that only fragments of 99953-19 (with little to no kernel material) were loaded in the NRAD reirradiation capsule. 
Four particles were reirradiated at a time. As depicted in Figure 3, four graphite holders, each containing a single particle, were loaded into a single aluminum container which was then inserted into NRAD at HFEF. NRAD is a $250 \mathrm{~kW}$ Training, Research, Isotopes, General Atomics (TRIGA) Mark II tank-type research reactor located below the main hot cell of HFEF at INL. At $250 \mathrm{~kW}$, the approximate one-group flux in NRAD is $5.2 \times 10^{12} \mathrm{n} / \mathrm{cm}^{2}$-s. NRAD Experimental Safety Analysis (ESA)-27 provides the technical basis for performing the reirradiation of previously irradiated AGR TRISO particles in NRAD (Laug 2017). The particles were reirradiated for four consecutive, 8-hour days. Reirradiation in NRAD will generate short-lived I-131 ( $\mathrm{t}_{1 / 2}=8.02$ days $)$ and Xe-133 $\left(\mathrm{t}_{1 / 2}=5.2\right.$ days $)$ that had decayed away shortly after the original AGR-2 irradiation test ended. Post-reirradiation heating testing enables assessment of the retention of I-131 and Xe-133 in the fuel at accident temperatures. All of the steps leading from sample preparation to pre-reirradiation gamma counting, reirradiation, post-reirradiation gamma counting, heating tests, and post-heating test gamma counting are discussed for the group of crushed and the group of cracked particles in (Stempien 2017a) and (Stempien 2017b), respectively.

After NRAD reirradiation, the particles in their graphite holders were removed from the aluminum irradiation capsule and gamma counted again to determine the fission product inventory prior to insertion in the FACS furnace for heating testing. Table 5 lists the post-NRAD/pre-FACS gamma activities for selected isotopes in the four particles used in the second reirradiation heating test. Table 5 also compares the pre- and post-reirradiation activities by taking a ratio of the pre-NRAD to post-NRAD activities. Note that for particles 99953-11, 99953-17, and 99953-39, tungsten shielding had to be placed between the particle and the detectors to reduce detector dead-time. This made it impossible to detect I-131 in those particles. The purpose of reirradiation was to generate short-lived isotopes, particularly I-131.

Unfortunately, the only particle where I-131 was detected in the post-NRAD/pre-FACS counts was 99953-19, which was a small kernel fragment or fragment of TRISO coating.

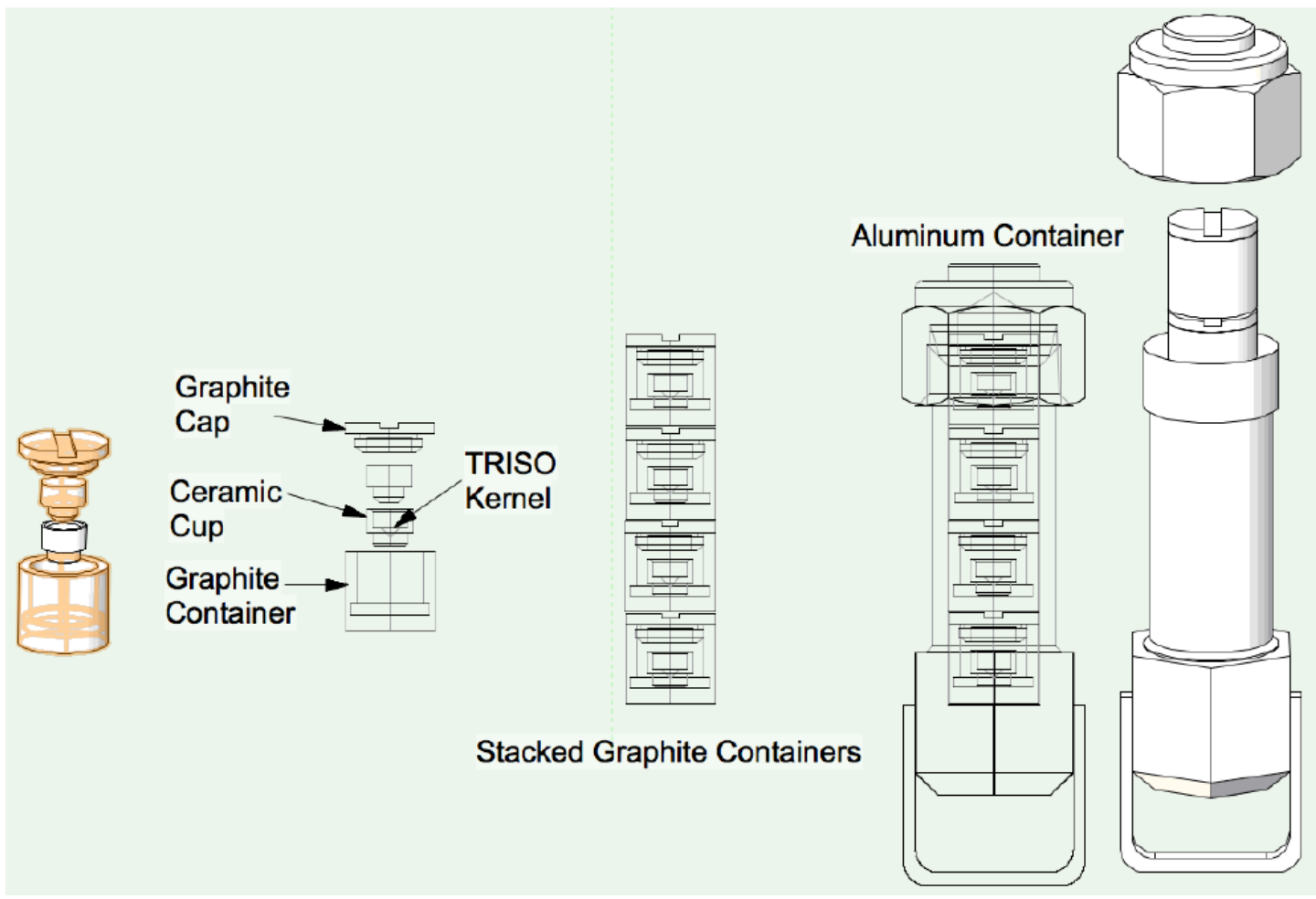

Figure 3. Individual alumina (ceramic) cups and graphite holders (containers) hold one particle each during reirradiation and FACS testing. The aluminum reirradiation container (capsule) holds four graphite containers at a time. 
Table 4. Activities of select isotopes in Group 2 particles after DLBL of AGR-2 Compact 6-4-1 and after particle cracking, and ratios of pre- to post-cracking activities are listed. (Ce/Pr-144, Eu-155, and $\mathrm{Ru} / \mathrm{Rh}-106$ were also measured, but are not shown below.) All activities and ratios are prior to reirradiation and heating and are referenced to 9/7/2017 at 8:00 AM.

\begin{tabular}{|c|c|c|c|c|}
\hline Particle ID\# & Ag-110m & Cs-134 & Eu-154 & Sb-125 \\
\hline \multicolumn{5}{|c|}{ Particle activity $(\mu \mathrm{Ci})$ measured after DLBL prior to cracking. } \\
\hline $99953-11$ & $1.028 \mathrm{E}-02$ & 19.701 & 1.948 & 1.823 \\
\hline $99953-17$ & 7.685E-03 & 18.990 & 1.803 & 1.633 \\
\hline 99953-19 & 9.253E-03 & 16.911 & 1.612 & 1.497 \\
\hline 99953-39 & 4.558E-03 & 18.801 & 1.767 & 1.620 \\
\hline \multicolumn{5}{|c|}{ Particle activity ( $\mu \mathrm{Ci}$ ) measured after cracking to obtain loose fuel kernel (post-cracking/pre-NRAD) } \\
\hline 99953-11 & $\mathrm{n} / \mathrm{a}$ & 19.130 & 1.796 & 1.695 \\
\hline $99953-17$ & $\mathrm{n} / \mathrm{a}$ & 18.550 & 1.806 & 1.902 \\
\hline 99953-19 & $\mathrm{n} / \mathrm{a}$ & 7.515E-02 & $6.682 \mathrm{E}-03$ & $6.310 \mathrm{E}-03$ \\
\hline 99953-39 & $\mathrm{n} / \mathrm{a}$ & 14.660 & 1.600 & 1.806 \\
\hline \multicolumn{5}{|c|}{ Ratio of cracked particle activity to pre-cracking activity. } \\
\hline 99953-11 & $\mathrm{n} / \mathrm{a}$ & $9.71 \mathrm{E}-01$ & $9.22 \mathrm{E}-01$ & 9.30E-01 \\
\hline 99953-17 & $\mathrm{n} / \mathrm{a}$ & 9.77E-01 & $1.00 \mathrm{E}+00$ & $1.16 \mathrm{E}+00$ \\
\hline 99953-19 & $\mathrm{n} / \mathrm{a}$ & 4.44E-03 & 4.15E-03 & $4.21 \mathrm{E}-03$ \\
\hline 99953-39 & $\mathrm{n} / \mathrm{a}$ & $7.80 \mathrm{E}-01$ & 9.06E-01 & $1.12 \mathrm{E}+00$ \\
\hline
\end{tabular}

n/a: denotes cases where no activity was detected or cases where ratios cannot be taken

Table 5. Activities of select isotopes in Group 2 particles after reirradiation in NRAD. (Ce/Pr-144, Eu-155, and Ru/Rh-106 were also measured, but are not shown below.) All activities are referenced to 9/7/2017 at 8:00 AM. Ratio of post-NRAD to pre-NRAD gamma activities.

\begin{tabular}{|c|c|c|c|c|c|}
\hline Particle ID\# & Ag-110m & Cs-134 & Eu-154 & $\mathrm{I}-131$ & Sb-125 \\
\hline \multicolumn{6}{|c|}{ Particle activity $(\mu \mathrm{Ci})$ post-NRAD reirradiation/pre-FACS heating testing } \\
\hline 99953-11* & $\mathrm{n} / \mathrm{a}$ & 18.687 & 1.876 & $\mathrm{n} / \mathrm{a}$ & 1.535 \\
\hline $99953-17 *$ & $\mathrm{n} / \mathrm{a}$ & 18.230 & 1.940 & $\mathrm{n} / \mathrm{a}$ & 1.878 \\
\hline $99953-19$ & 4.144E-02 & 8.180E-02 & $\mathrm{n} / \mathrm{a}$ & 1.313E-01 & $\mathrm{n} / \mathrm{a}$ \\
\hline 99953-39* & $\mathrm{n} / \mathrm{a}$ & 13.006 & 1.877 & $\mathrm{n} / \mathrm{a}$ & 1.416 \\
\hline Total & 4.144E-02 & 50.004 & 5.693 & 1.313E-01 & 4.829 \\
\hline \multicolumn{6}{|c|}{ Ratio of post-NRAD/pre-FACS activity to pre-NRAD/post-cracking activity } \\
\hline 99953-11 & $\mathrm{n} / \mathrm{a}$ & 9.77E-01 & $1.04 \mathrm{E}+00$ & $\mathrm{n} / \mathrm{a}$ & 9.06E-01 \\
\hline 99953-17 & $\mathrm{n} / \mathrm{a}$ & 9.83E-01 & $1.07 \mathrm{E}+00$ & $\mathrm{n} / \mathrm{a}$ & $9.88 \mathrm{E}-01$ \\
\hline 99953-19 & $\mathrm{n} / \mathrm{a}$ & $1.09 \mathrm{E}+00$ & $\mathrm{n} / \mathrm{a}$ & $\mathrm{n} / \mathrm{a}$ & $\mathrm{n} / \mathrm{a}$ \\
\hline 99953-39 & $\mathrm{n} / \mathrm{a}$ & 8.87E-01 & $1.17 \mathrm{E}+00$ & $\mathrm{n} / \mathrm{a}$ & 7.84E-01 \\
\hline
\end{tabular}




\subsection{First Reirradiation and Terminated Heating Test}

The crushed particles listed in Table 2 were the first group to undergo reirradiation in NRAD. The particles were gamma counted after crushing and loading into the graphite holders, and gamma counted again following reirradiation. (Results from the gamma surveys are still being processed, as discussed in Section 2.3.) After post-NRAD gamma counting, the particles remained in the alumina cups inside the capped graphite holders (pictured in Figure 3), and the four graphite holders were loaded onto a tantalum sample holder (stage) in the FACS furnace.

Figure 4 shows the temperature profile programmed into the FACS furnace temperature controller, the actual temperature measured by the FACS Furnace \#1 thermocouple, and the planned condensation plate exchange schedule. Problems were encountered during the first scheduled plate exchange (scheduled at an elapsed time of 3.5 hours and a furnace temperature of $300^{\circ} \mathrm{C}$ ) which prevented the exchange and led to the early termination of the test after only 3.65 hours and a temperature of only $300^{\circ} \mathrm{C}$. The cold finger that holds the condensation plate in the FACS furnace was not properly aligned. The cold finger alignment was checked, and plate changes were made at ambient temperature prior to the start of the test; however, the alignment changed enough when the furnace was hot that successful plate changes could not be carried out. Prior to subsequent tests, the cold finger alignment has since been tuned, and the operation of plate exchanges was verified while the furnace was at $1600^{\circ} \mathrm{C}$. The one condensation plate used during the test was gamma counted on the HFEF out-of-cell gamma station, and while the data are still being analyzed, it is notable that I-131 (which was produced during NRAD reirradiation) was measured on this plate after a 2-hour ramp to $300^{\circ} \mathrm{C}$ and 1.5 hours held at $300^{\circ} \mathrm{C}$. The FGMS system was operated during this 3.5 hour period of time and detected both $\mathrm{Kr}-85$ (a long-lived fission gas) and Xe-133 (a short-lived fission gas generated from the reirradiation in NRAD). Interestingly, I-131 was also detected in the FGMS traps. The FGMS detectors are not calibrated for I-131, so the I-131 could be detected, but not well quantified. Once the post-NRAD/pre-FACS particle counts have been analyzed, the radioisotope activities measured on the condensation plate and in FGMS can be compared to them.

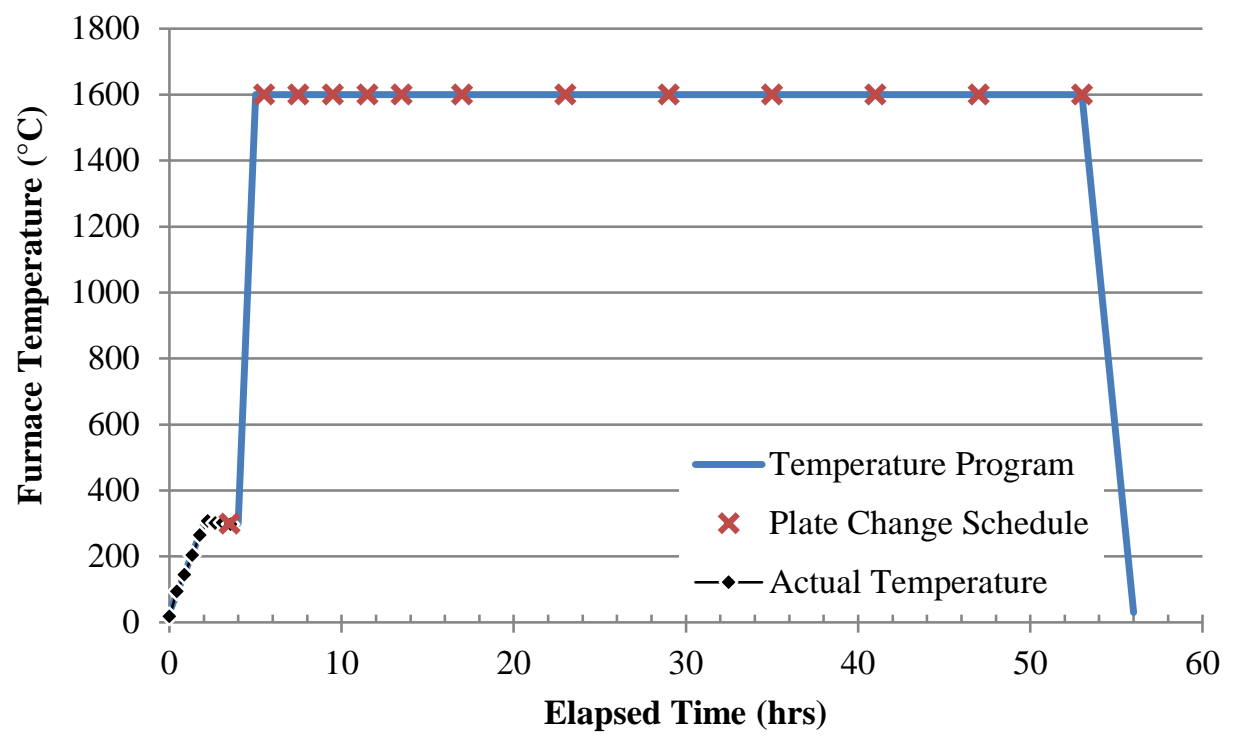

Figure 4. Planned temperature program, actual temperature, and planned condensation-plate change schedule. Test was terminated after 3.65 hours. 


\subsection{Second Reirradiation Heating Test}

\subsubsection{Temperature program and condensation plate exchanges}

The cracked particles from AGR-2 Compact 6-4-1 listed in Table 3 were the second group of particles to undergo reirradiation in NRAD and post-reirradiation heating testing in the FACS furnace. After I-131 was detected in the FGMS traps from the first reirradiation heating test (Section 2.4), a silverzeolite filter was put in the gas line prior to the FGMS and prior to the gas line exiting the cell at HFEF. This filter successfully prevented I-131 from reaching the FGMS during this second reirradiation heating test. Figure 5 shows the planned furnace temperature program and condensation plate exchange schedule from (Stempien 2017b). Figure 6 shows the actual temperature program and condensation-plate exchanges performed during the test. As depicted in Figure 6, the test started up normally, the test temperature of $1600^{\circ} \mathrm{C}$ was reached, and the scheduled condensation-plate changes were performed; however, after a total time of 8.8 hours, the test was stopped and the furnace cooled. This stop was caused by an apparent blockage in the system that caused an increase in the gas pressure required to maintain helium flow through the FACS furnace. Just prior to the temporary stoppage of the test at 8.8 hours, the gas pressure in the FACS furnace was approaching the alarm point. It was assumed that the blockage was at the silver-zeolite filter. A new filter was put in place, the test was restarted, the planned test temperature of $1600^{\circ} \mathrm{C}$ was reached, and condensation plate changes resumed. A total of 8 plate exchanges were performed, and six of those were at the test temperature of $1600^{\circ} \mathrm{C}$. After a total heating time of 19.7 hours (approximately 11 hours after the first stoppage), the system became plugged again, and the test was terminated. It was discovered that the silver-zeolite filter contained adsorbed moisture that was released and froze at the entrance to the FGMS. These filters will be dried at elevated temperatures and stored with desiccants prior to use in the FACS system for future reirradiation heating tests.

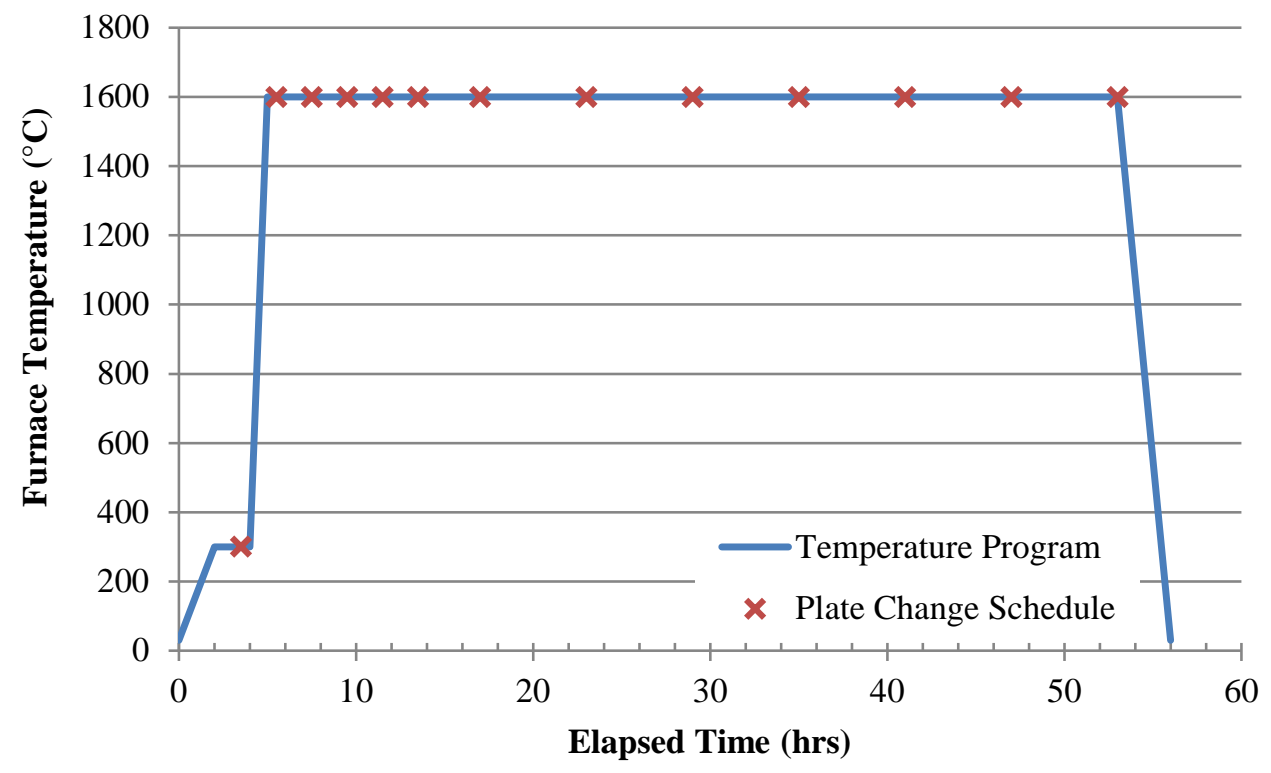

Figure 5. Planned temperature program and condensation plate change schedule from (Stempien 2017b). 


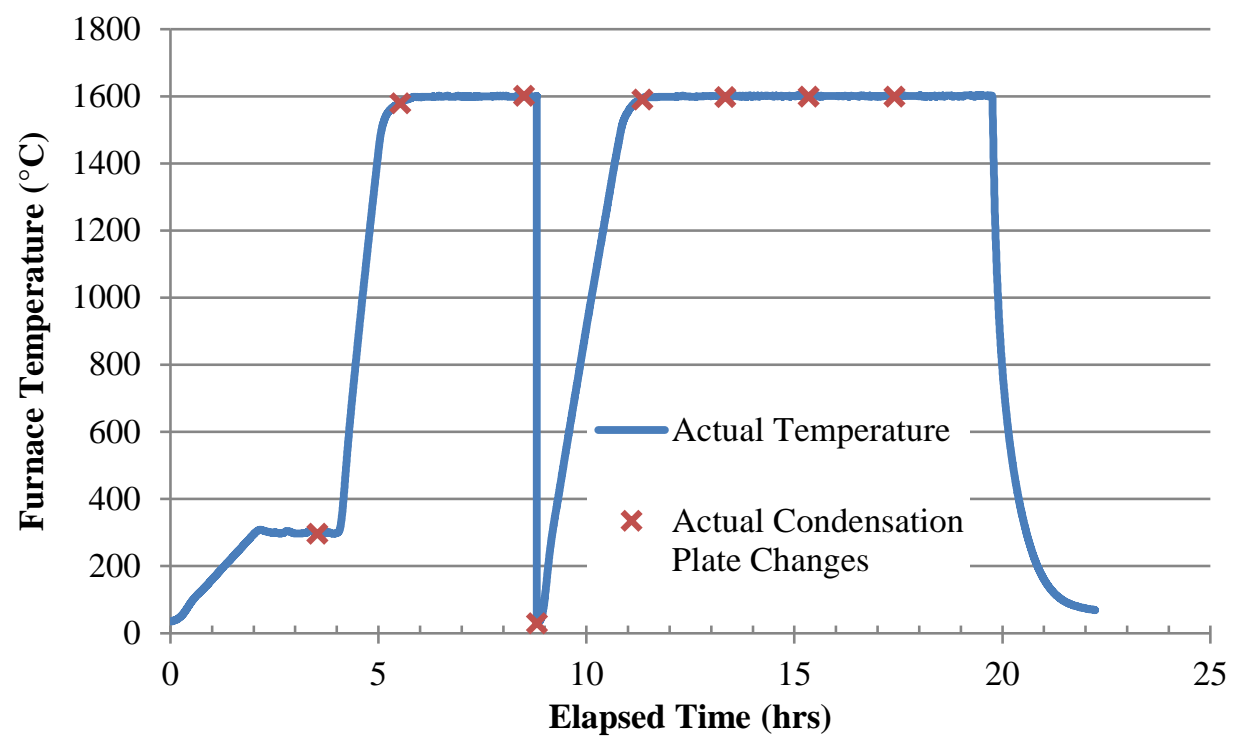

Figure 6. Actual furnace temperature and temperature and time of condensation plate changes. Test was stopped after the first 8.8 hours, restarted, and finally stopped early after a total of 19.7 hours (approximately 10 hours at $1600^{\circ} \mathrm{C}$ ).

\subsubsection{Fission Product Releases}

Figure 7 summarizes the measured activity on the condensation plates and in the FGMS. Note that Cs-137 and Eu-155 were also measured on the condensation plates; however, only Cs-134 and Eu-154 are plotted. The measured Cs-137 and Cs-134 are generally in good agreement, but due to trace contamination of the longer-lived Cs-137 in the hot cell, Cs-137 readings are usually biased higher than Cs-134. Europium-154 was measured on all condensation plates; however, Eu-155 was only detected on 4 of 8 condensation plates. Europium-154 has higher-energy gamma rays that are more consistently measured (with lower error) than Eu-155; therefore, only Eu-154 is plotted to represent europium. All activities in this figure are referenced to the date 9/7/2017 8:00 AM. Raw activities measured on the plates were adjusted according to the measured FACS furnace condensation plate collection efficiencies listed in Table 6. Except for Eu-154, the majority of the release occurred prior to the first test stoppage at 8.8 hours. When the test resumed, additional Eu-154 was measured. This demonstrates the more gradual release of Eu-154 from the assembly of the particle in the alumina cup inside the graphite holder. The Core Conduction Cooldown Test Facility at Oak Ridge National Laboratory uses a graphite holder for all compact safety tests. These tests show that 50 to $90 \%$ of the europium (and 3 to $70 \%$ of the strontium) released from the compact is retained in the graphite sample holder (Hunn et al. 2017). Thus, the apparent rate of europium release from this FACS test of the reirradiated particles is expected to be significantly affected by hold up in the graphite particle holders.

After the heating test in the FACS furnace, the particles and holders were gamma counted. First, the assembly of the particle, alumina cup, and graphite holder was counted as a single piece (see Figure 3). Then the graphite holder was opened, and the particle/alumina cup was removed. The particle could not be separated from the cup, so the particle and cup were counted together, and the graphite holder was counted separately. It was assumed that the activity measured on the particle/cup was all retained in the particle and that the cup did not hold up any fission products. The temperature of the particles during reirradiation was not known. Analysis has shown that the temperature of the aluminum reirradiation capsule should be less than $1^{\circ} \mathrm{C}$ warmer than the NRAD water temperature of $40^{\circ} \mathrm{C}$ (Laug 2017); however, a thermal analysis will be needed to determine the particle temperatures during reirradiation. In 
this report, it was assumed that the particles were not significantly warmer than $40^{\circ} \mathrm{C}$ and that no radionuclides were released from the particles during reirradiation.

Figure 8 shows the ratio of the condensation plate activity-versus-time to the total activity measured in all four particles after reirradiation and prior to FACS testing (see row labeled "Total" in Table 5). Thus, Figure 8 represents the total fractional release from the particles and their graphite holders. Note that some releases from the particles are held up in the graphite particle holders used during reirradiation and FACS testing. The rows grouped next to \#8 in Table 7 show that up to 3\% of the Cs-134 was retained in the graphite holder for particle \#99953-19, up to $42 \%$ of the Eu-154 was retained in the particle 99953-39 holder, and possibly 20\% of the I-131 from 99953-19 was retained in its graphite holder. Figure 8 shows that from the four particles overall, Cs-134 and Sb-125 were released from the particle and graphite holder at approximately 100\%, and total Eu-154 release was 21.5\%. Since the Sb-125 fractions shown in Figure 8 are greater than 1, this means greater activity was counted on the condensation plates than was counted in the particles. Because the particles are the only source of Sb-125 in the test, a ratio significantly above 1 suggests that there was some inconsistency in the gamma counting that requires additional analysis. Iodine- 131 was measured on every condensation plate except for the first plate exchanged 30 minutes prior to the start of the ramp from $300^{\circ} \mathrm{C}$ to $1600^{\circ} \mathrm{C}$. However, because the post-NRAD/pre-FACS particle counts had to be performed with tungsten shielding to reduce the detector dead time, I-131 was not counted in three of the particles prior to the FACS test. Since I-131 was not successfully detected in the post-NRAD/pre-FACS counts, I-131 is not shown in Figure 8. One purpose of this test and the first reirradiation was to determine whether I-131 could be reliably measured in particles following reirradiation. Given the difficulty in counting I-131 in reirradiated particles, physics calculations will be performed to predict the post-reirradiation inventory in samples prior to heating tests.

Table 7 shows the total activities measured in different components (particles, graphite holders, and plates) after the FACS heating test. All activities are referenced to 9/7/2017 at 8:00 AM. The numbers (1 through 8 ) in the first column of Table 7 will be used to reference groups of data in this paragraph. Rows grouped 1 through 3 show the measured activities for the graphite holder and particles (counted together prior to disassembly after the heating test), the activities for the particles separated from the graphite holder, and the activities for the graphite holder counted separately from the particles. The group 4 rows give essentially the fraction of the post-NRAD/pre-FACS activity that was retained in the particles after the FACS test. Subtracting the fractions in the group 4 rows from one gives the fraction of the particle inventory released during the FACS test. The row numbered 5 gives the total activity measured on all eight condensation plates. The row numbered 6 is a check on the mass balance of the experiment: values should be near 1 . If the values were not near 1 , then this indicates large error in the gamma counting or that a fragment of the samples was lost. The large discrepancy in the I-131 ratio is due to the fact that I-131 was not counted in three of the four particles (because the tungsten shielding required to reduce detector dead time attenuated the I-131 gamma rays). The row numbered 7 compares the total post-FACS activity measured outside of the particles (on the condensation plates and graphite holders) to the total post-NRAD/pre-FACS activity in the particles. Group 7 is another way to derive the fraction of the particle inventories released during FACS testing. The Group 7 numbers are not always consistent with 1 minus the group 4 numbers because of the difficulty of counting the post-NRAD particles. As discussed earlier in this section, group 8 in Table 7 gives a measure of the retention of isotopes in the graphite holders used to hold the particles throughout the experiment. Group 8 shows that a significant amount of the Eu-154 released from the kernels was retained in the graphite holders. 


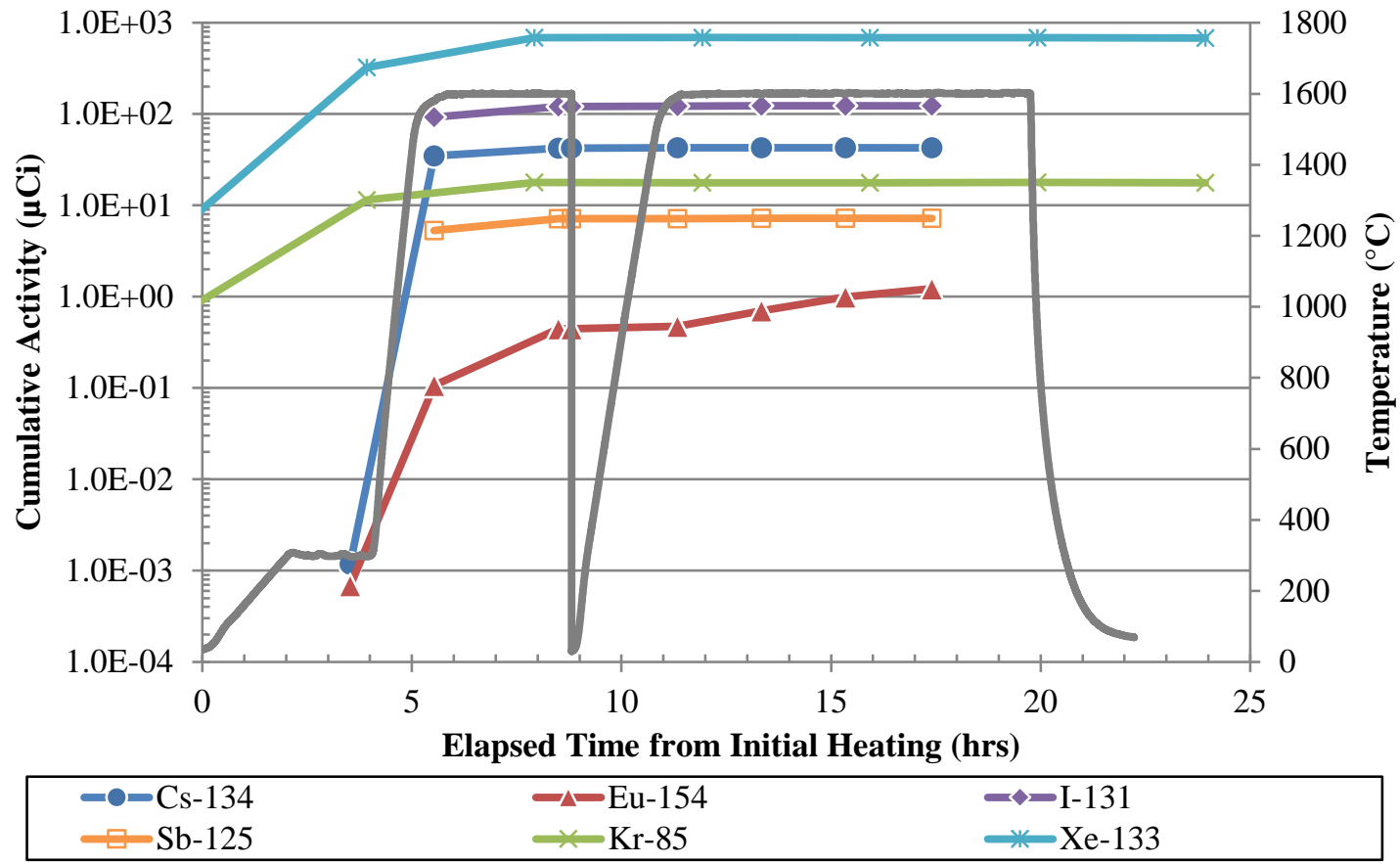

Figure 7. Total measured activities of condensable fission products on condensation plates and of noblegas fission products in the FGMS as a function of test time. All activities are reported at the reference time of 9/7/2017 at 8:00 AM.

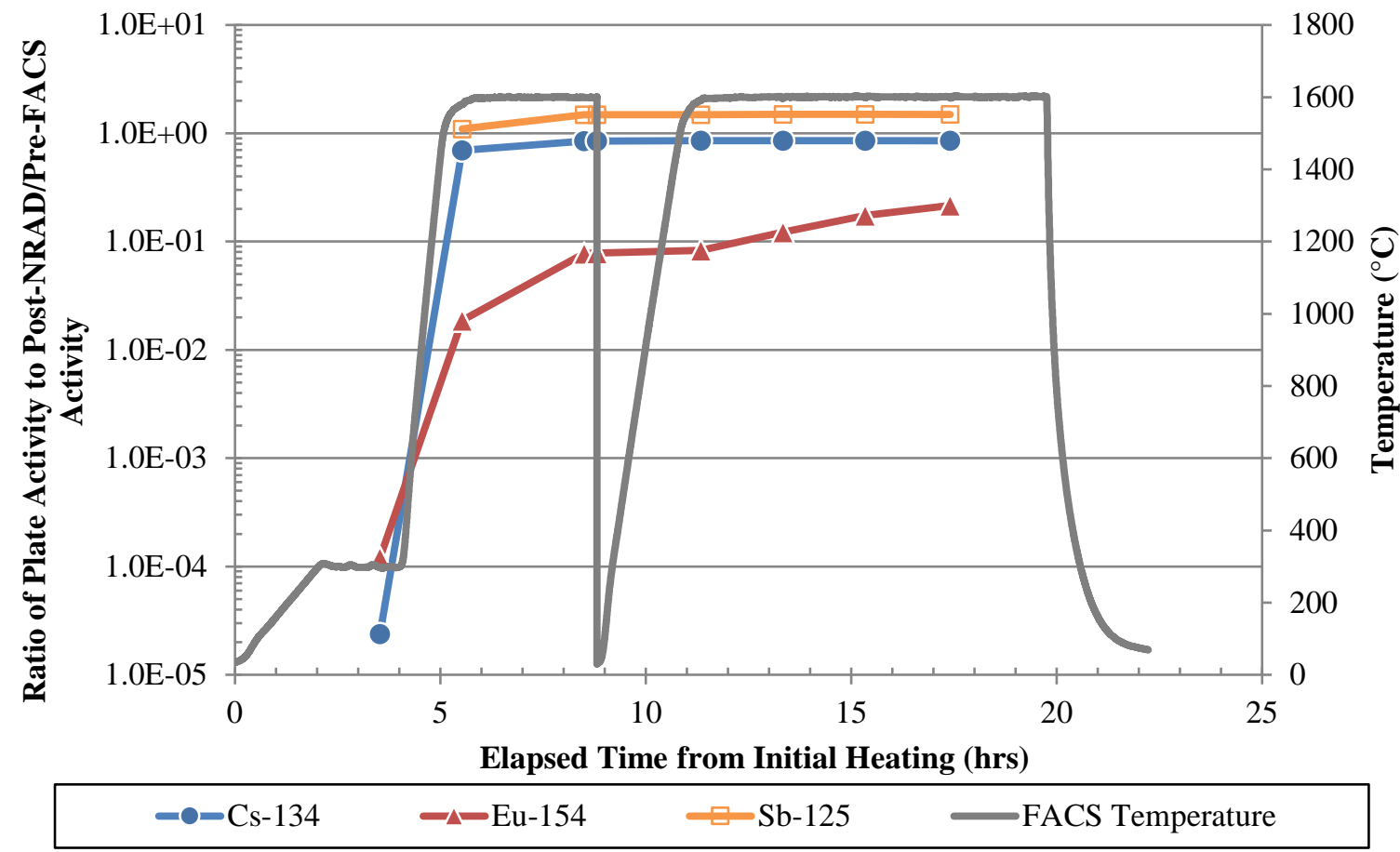

Figure 8. Ratio of the cumulative condensation-plate activity versus time to the total activity measured in all four particles after NRAD/before FACS. Values of 1.0 indicate complete release. 
Table 6. FACS furnace condensation plate collection efficiencies at $1600^{\circ} \mathrm{C}$.

\begin{tabular}{|c|c|}
\hline Element & FACS Condensation Plate Collection Efficiency at $1600^{\circ} \mathrm{C}$ \\
\hline silver $^{\mathrm{a}}$ & 0.503 \\
\hline cesium $^{\mathrm{a}}$ & 0.661 \\
\hline europium $^{\mathrm{a}}$ & 0.286 \\
\hline iodine & 0.479 \\
\hline antimony $^{\mathrm{b}}$ & 0.378 \\
\hline strontium $^{\mathrm{a}}$ & 0.333 \\
\hline
\end{tabular}

Table 7. Post-FACS test activities of particles, graphite holders, and condensation plates. All activities are referenced to 9/7/2017 8:00 AM. Ratios comparing measured activities are listed.

\begin{tabular}{|c|c|c|c|c|c|c|c|}
\hline & Ag-110m & Cs-134 & Cs-137 & Eu-154 & I-131 & Sb-125 \\
\hline \multicolumn{8}{|c|}{ Post-NRAD/Post-FACS Activity ( $\mu \mathrm{Ci}$ ) in Particles and Graphite Holders Counted Together } \\
\hline \multirow{5}{*}{1} & $99953-11$ & $\mathrm{n} / \mathrm{a}$ & $\mathrm{n} / \mathrm{a}$ & 6.04E-02 & 7.59E-01 & $\mathrm{n} / \mathrm{a}$ & 3.82E-02 \\
\hline & $99953-17$ & $\mathrm{n} / \mathrm{a}$ & 9.99E-03 & 8.67E-02 & 5.80E-01 & 7.05E-02 & 3.92E-02 \\
\hline & 99953-19 & $\mathrm{n} / \mathrm{a}$ & 2.53E-03 & 4.37E-02 & 4.90E-01 & 2.98E-02 & $\mathrm{n} / \mathrm{a}$ \\
\hline & 99953-39 & $\mathrm{n} / \mathrm{a}$ & $\mathrm{n} / \mathrm{a}$ & 4.44E-02 & 9.03E-01 & $\mathrm{n} / \mathrm{a}$ & 3.48E-02 \\
\hline & Total & $\mathrm{n} / \mathrm{a}$ & 1.25E-02 & 2.35E-01 & $2.73 \mathrm{E}+00$ & $1.00 \mathrm{E}-01$ & $1.12 \mathrm{E}-01$ \\
\hline \multicolumn{8}{|c|}{ Post-NRAD/Post-FACS Activity $(\mu \mathrm{Ci})$ in Particles Only } \\
\hline \multirow{5}{*}{2} & $99953-11$ & $\mathrm{n} / \mathrm{a}$ & $\mathrm{n} / \mathrm{a}$ & 2.36E-03 & $1.31 \mathrm{E}-01$ & $\mathrm{n} / \mathrm{a}$ & 3.42E-02 \\
\hline & 99953-17 & $\mathrm{n} / \mathrm{a}$ & $1.72 \mathrm{E}-03$ & $1.28 \mathrm{E}-02$ & 2.82E-02 & 2.77E-02 & $\mathrm{n} / \mathrm{a}$ \\
\hline & 99953-19 & $\mathrm{n} / \mathrm{a}$ & 3.70E-05 & 2.14E-03 & $1.60 \mathrm{E}-04$ & $\mathrm{n} / \mathrm{a}$ & $\mathrm{n} / \mathrm{a}$ \\
\hline & 99953-39 & $\mathrm{n} / \mathrm{a}$ & $\mathrm{n} / \mathrm{a}$ & $4.01 \mathrm{E}-03$ & $1.61 \mathrm{E}-01$ & $\mathrm{n} / \mathrm{a}$ & $3.42 \mathrm{E}-02$ \\
\hline & Total & $\mathrm{n} / \mathrm{a}$ & $1.76 \mathrm{E}-03$ & 2.13E-02 & 3.20E-01 & 2.77E-02 & 6.84E-02 \\
\hline \multicolumn{8}{|c|}{ Post-NRAD/Post-FACS Activity ( $\mu \mathrm{Ci}$ ) in Graphite Holder Only } \\
\hline \multirow{5}{*}{3} & 99953-11 & $\mathrm{n} / \mathrm{a}$ & 3.19E-03 & 5.15E-02 & $6.24 \mathrm{E}-01$ & $\mathrm{n} / \mathrm{a}$ & $\mathrm{n} / \mathrm{a}$ \\
\hline & 99953-17 & $\mathrm{n} / \mathrm{a}$ & 7.13E-03 & $6.61 \mathrm{E}-02$ & 5.34E-01 & $\mathrm{n} / \mathrm{a}$ & $\mathrm{n} / \mathrm{a}$ \\
\hline & 99953-19 & $\mathrm{n} / \mathrm{a}$ & $2.42 \mathrm{E}-03$ & $3.78 \mathrm{E}-02$ & 4.86E-01 & 2.62E-02 & $\mathrm{n} / \mathrm{a}$ \\
\hline & 99953-39 & $\mathrm{n} / \mathrm{a}$ & 3.36E-03 & 3.62E-02 & 7.84E-01 & $\mathrm{n} / \mathrm{a}$ & 1.73E-03 \\
\hline & Total & $\mathrm{n} / \mathrm{a}$ & $1.61 \mathrm{E}-02$ & 1.92E-01 & $2.43 \mathrm{E}+00$ & 2.62E-02 & $1.73 \mathrm{E}-03$ \\
\hline \multicolumn{8}{|c|}{ Ratio of Post-NRAD/Post-FACS Particles-Only Activity to Post-NRAD/Pre-FACS Particle Activity } \\
\hline \multirow{4}{*}{4} & 99953-11 & $\mathrm{n} / \mathrm{a}$ & $\mathrm{n} / \mathrm{a}$ & 3.30E-05 & $6.96 \mathrm{E}-02$ & $\mathrm{n} / \mathrm{a}$ & 2.23E-02 \\
\hline & $99953-17$ & $\mathrm{n} / \mathrm{a}$ & 9.43E-05 & $1.57 \mathrm{E}-04$ & 1.45E-02 & $\mathrm{n} / \mathrm{a}$ & $\mathrm{n} / \mathrm{a}$ \\
\hline & 99953-19 & $\mathrm{n} / \mathrm{a}$ & 4.52E-04 & 5.63E-03 & $\mathrm{n} / \mathrm{a}$ & $\mathrm{n} / \mathrm{a}$ & $\mathrm{n} / \mathrm{a}$ \\
\hline & 99953-39 & $\mathrm{n} / \mathrm{a}$ & $\mathrm{n} / \mathrm{a}$ & $6.61 \mathrm{E}-05$ & 8.59E-02 & $\mathrm{n} / \mathrm{a}$ & 2.42E-02 \\
\hline \multicolumn{8}{|c|}{ Total Condensation Plate Activity $(\mu \mathrm{Ci})$ at reference date } \\
\hline 5 & Total of all plates & $\mathrm{n} / \mathrm{a}$ & 4.26E +01 & $2.17 \mathrm{E}+02$ & $1.23 \mathrm{E}+00$ & $1.23 \mathrm{E}+02$ & $7.20 \mathrm{E}+00$ \\
\hline \multicolumn{8}{|c|}{ Ratio of plates (\#5) plus particles (\#2) plus graphite holders (\#3) to post-NRAD/Pre-FACS counts (Table 5) } \\
\hline 6 & Ratio & $\mathrm{n} / \mathrm{a}$ & 8.53E-01 & $1.02 \mathrm{E}+00$ & $1.18 \mathrm{E}+00$ & $2.46 \mathrm{E}+00$ & $1.52 \mathrm{E}+00$ \\
\hline
\end{tabular}


Table 7. (continued).

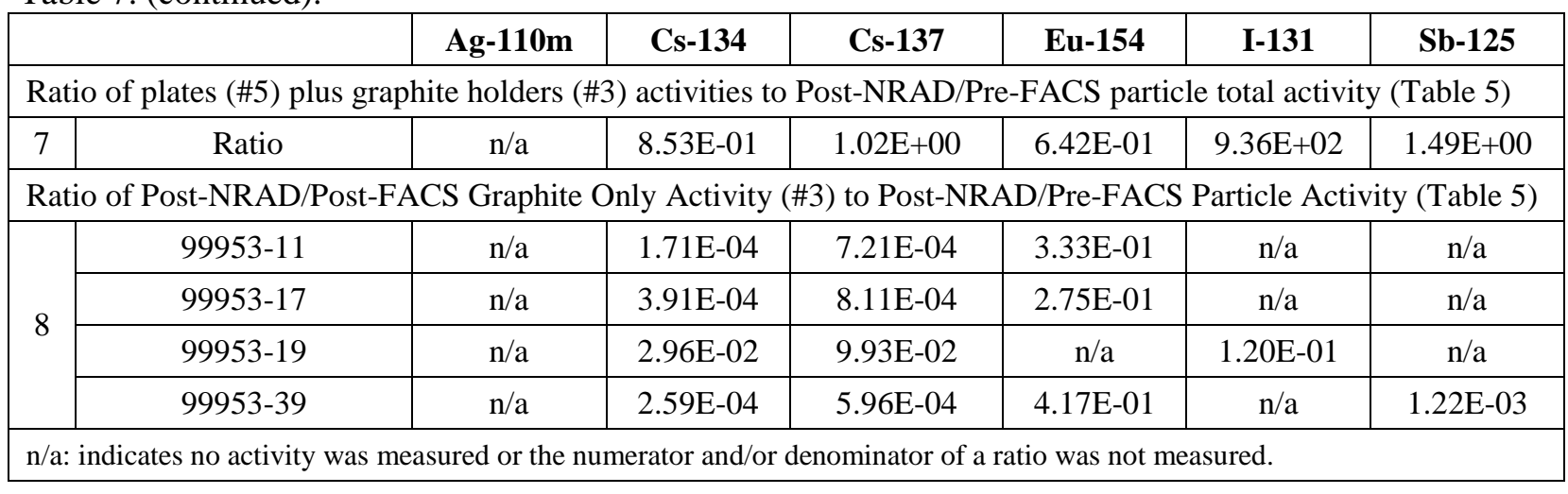

Figure 9 shows the activity of Kr-85 and Xe-133 measured in the FGMS during the FACS heating test. Since the Kr-85 inventory in the particles after reirradiation and prior to heating could not be measured, this inventory was estimated, and an estimated fractional Kr-85 value was also plotted in Figure 9. To calculate this fraction, the Kr-85 activity measured in the FGMS traps was decay-corrected back to EOI+1 day, and this activity was divided by the Kr-85 activity calculated (from Sterbentz 2014) to exist in 3 intact particles at EOI+1 day. The inventory predicted in three particles was used here because the ratios in Table 4 show that the majority of the pre-cracking inventory of particles 99953-11, 99953-17, and 99953-39 was present in the kernels after cracking; however, after cracking, only about 0.4\% of the pre-cracking inventory was measured for 99953-19.

Figure 9 shows that the fractional amount of Kr-85 detected in the FGMS is $66 \%$ of the predicted inventory in three average particles at the end of the AGR-2 irradiation. An oddity in Figure 9 is that the FMGS activity of $\mathrm{Kr}-85$ and $\mathrm{Xe}-133$ near $\mathrm{t}=0$ is a significant portion of the total released activity. This could be due to rapid release upon starting heating. The fact that a substantial fraction of Kr-85 (66\%) was measured suggests that much of the Kr-85 content in the particles after the initial irradiation in ATR remained in the kernels after cracking and after reirradiation, prior to the heating test. A similar comparison was done for the $1600^{\circ} \mathrm{C}$ heating test of five loose kernels ${ }^{\mathrm{b}}$ from AGR-1 Compact 5-3-1 (Stempien 2016), where 45\% of the inventory predicted in 5 particles after the AGR-1 irradiation was detected in the FGMS during that heating test.

The data presented in this section are preliminary, and additional analyses are planned. A physics calculation specifically for the AGR-2 Compact 6-4-1 particle reirradiation discussed in this report is needed to compare to the Xe-133 activity measured in the FGMS and the I-131 measured on the condensation plates. All the Xe-133 and I-131 would have been produced from the reirradiation; however, significant Kr-85 could have existed from the initial irradiation in ATR. The amount of Kr-85 measured in the FGMS supports this notion. The amount of Kr-85 (and all other long-lived isotopes) produced during reirradiation is expected to be insignificant compared to the amount produce during irradiation in ATR. This could also be verified with physics calculations. The condensation plates will be stripped and analyzed for Sr-90. The particles and graphite holders could also be leached/burned to analyze for Sr-90.

b These loose kernels were cracked particles with the kernel separated from the coatings. This preparation was very similar to that used here for the second group of AGR-2 Compact 6-4-1 particles. 


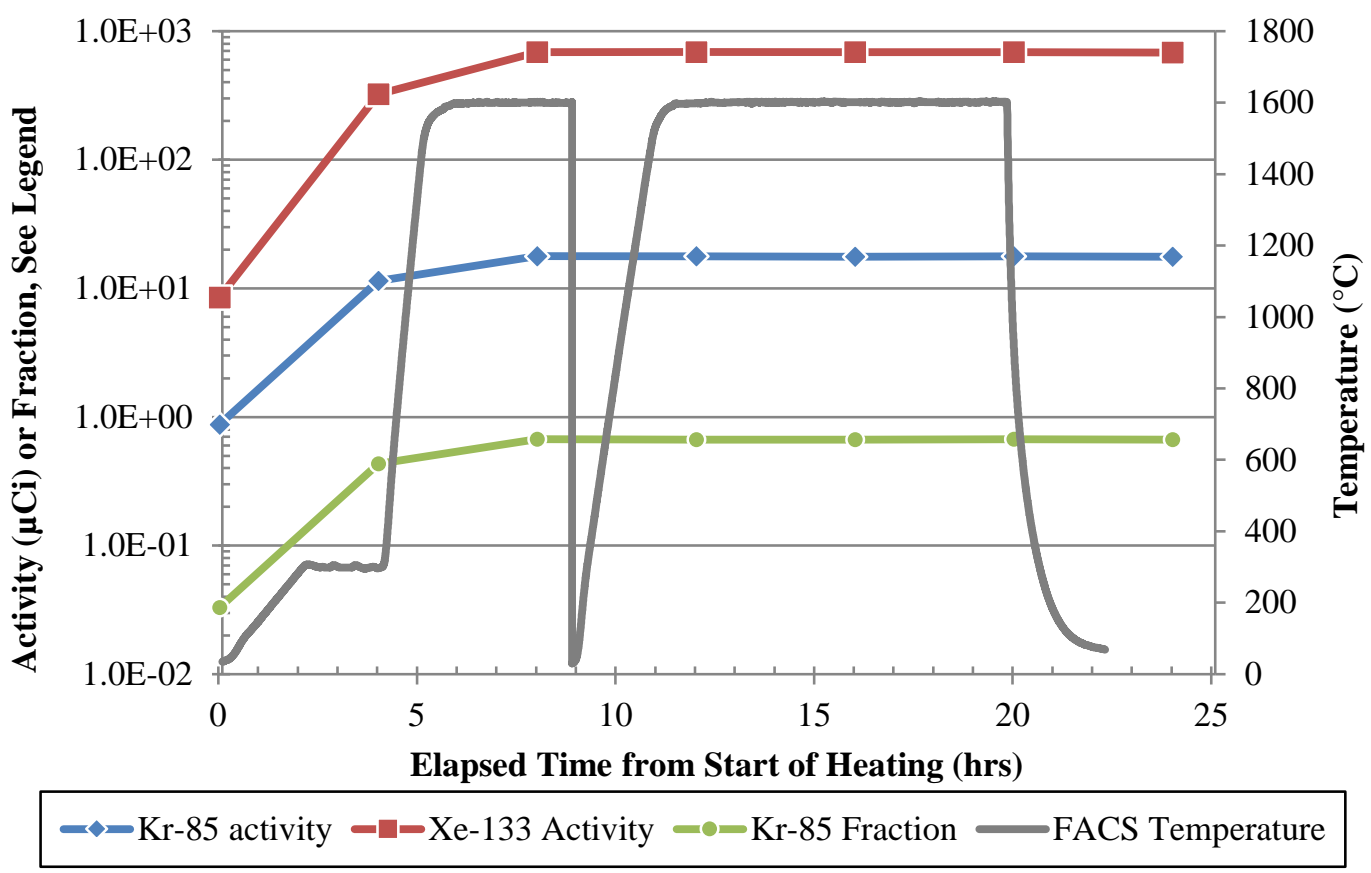

Figure 9. Activities of noble fission gases Kr-85 and Xe-133 measured in the FGMS during heating of group 2 cracked fuel particles/bare kernels. Activities reported at reference time of 9/7/2017 at 8:00 AM. Kr-85 activity was decay-corrected to EOI+1 day and compared to the activity in three particles predicted by physics calculations from (Sterbentz 2014).

\section{AGR-3/4 COMPACT 3-2 AND 10-4 HEATING TESTS}

\subsection{Compact Fabrication and Irradiation Properties}

One feature of AGR-3/4 that sets it apart from AGR-1 and AGR-2 is the incorporation of 20 DTF particles in each compact, in addition to the approximately 1872 TRISO-coated driver fuel particles. Fuel kernels in DTF particles were coated only with a thin (20 $\mu \mathrm{m}$ thick) pyrocarbon layer. This layer was intentionally fabricated with a high anisotropy, such that it would likely fail during the irradiation (Collin 2015c), resulting in up to 20 exposed fuel kernels per compact. Driver particle fuel kernels were fully TRISO-coated with the buffer layer, IPyC, SiC, and OPyC. In summary, each AGR-3/4 compact contains approximately 1872 driver fuel particles and precisely 20 DTF particles.

All AGR-3/4 fuel particles (both driver particles and DTF particles) contain low-enriched UCO (a uranium carbide, uranium oxide mixture) fuel kernels approximately $350 \mu \mathrm{m}$ in diameter, manufactured at BWX Technologies Nuclear Operations Group (Lynchburg, VA). The U-235 enrichment was 19.7\%. As shown at right in Figure 10, the DTF particles (highlighted in red) were aligned in each compact roughly along the compact radial centerline. The white circles in Figure 10 are the driver particles. The DTF particles were fabricated at Oak Ridge National Laboratory (ORNL) by applying a single 20- $\mu$ m-thick pyrolytic carbon coating to the kernels produced at BWX Technologies Nuclear Operations Group. Driver fuel particles were fabricated at ORNL by applying TRISO coatings to the kernels, with the following average thickness for each layer:

Buffer: $109.7 \mu \mathrm{m}$

IPyC: $40.4 \mu \mathrm{m}$

SiC: $33.5 \mu \mathrm{m}$

OPyC: $41.3 \mu \mathrm{m}$. 
As with AGR-1 and AGR-2, AGR-3/4 compacts are right circular cylinders comprised of thousands of TRISO-coated fuel particles in a graphitic matrix. The graphitic matrix material is composed of multiple types of graphite and a carbonized phenolic resin. AGR-3/4 fuel compacts were fabricated at ORNL. The compacts are nominally $12.3 \mathrm{~mm}$ in diameter and $12.5 \mathrm{~mm}$ long (in contrast to the AGR-1 and AGR-2 compacts, which were approximately $25 \mathrm{~mm}$ long). A summary of AGR-3/4 fuel properties is provided in the AGR-3/4 Experiment Irradiation Test Plan (Collin 2015c). Detailed characterization data of the fuel particles and compacts have been provided by ORNL (Hunn and Lowden 2007; Hunn, Trammel, and Montgomery 2011; Kercher et al. 2011). Phase 2 of the AGR-3/4 PIE activities are outlined in (Demkowicz 2017). In the X-Y compact naming convention, $X$ denotes the capsule number, and Y denotes the level of the compact within the capsule (with level 1 at the bottom and level 4 at the top of the capsule). In AGR-3/4 there were four compacts per capsule. Thus, Compact 3-2 is the second compact from the bottom of Capsule 3, and Compact 10-4 is the top compact from Capsule 10.

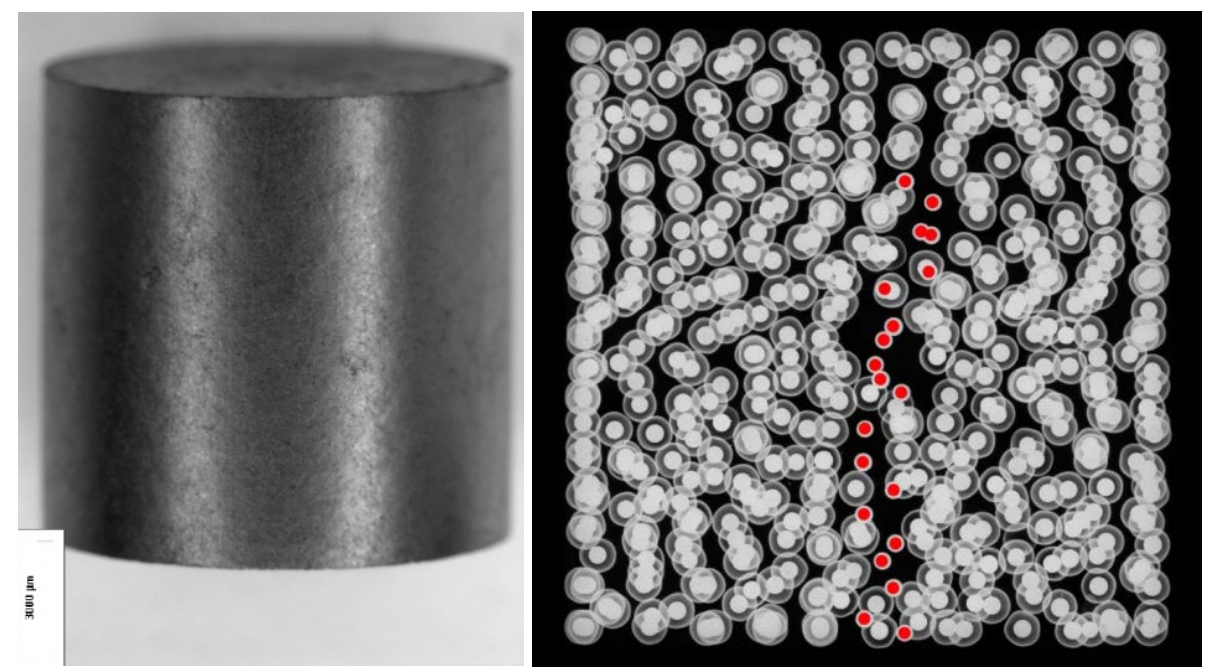

Figure 10. Image of AGR-3/4 fuel compact (left) and x-ray cross section (right) (Hunn, Trammell, and Montgomery 2011). DTF particles are highlighted with red dots in the x-ray at right.

Figure 11 plots the time-averaged, volume averaged (TAVA) irradiation temperature and fast fluence for each of the four compacts in each of the twelve AGR-3/4 capsules. Moving from left to right on the $\mathrm{x}$-axis, compacts are plotted in order, from the bottom of the test train to the top. The sine-shape of the axial fluence profile is clearly visible, but the axial variation in the TAVA temperature is flatter. The fast fluence and TAVA irradiation temperature for Compacts 3-2 and 10-4 are highlighted in Figure 11. The UCO fuel kernel lot is G37V-20-69303, the TRISO-coated driver fuel particle lot is LEU03-09T (renamed as LEU03-10T), and the DTF particle lot is LEU03-07DTF. Additional fabrication parameters and elements of the irradiation history specific to AGR-3/4 Compact 3-2 and Compact 10-4 are listed in Table 8 and Table 9, respectively.

The estimated number of DTF particle failures per AGR-3/4 irradiation capsule is listed in Table 10 Based on experience from AGR-1, it is very unlikely that any driver particles failed during the irradiation; therefore, all detected in-pile particle failures are assumed to be DTF failures. Since there are only 80 DTF particles per capsule, a combination of measurement uncertainty and calculational biases in the physics analyses may explain why greater than 80 DTF particle failures are listed in the maximum and best-estimate columns for Capsule 3. Given that the best-estimate value significantly exceeds 80 , it appears likely that all 20 DTF particles failed in each of the four compacts in Capsule 3. Thus, 20 failed DTF particles are expected to be present in Compact 3-2.

Using the maximum and minimum values for Capsule 10, if each Capsule 10 compact is assumed to have the same number of failed DTF particles, then it is estimated that between 9 and 19 failed DTF 
particles are present in each compact after irradiation. However, there is no evidence at the moment to suggest that the number of failed DTF particles is the same for each of the four Capsule 10 compacts. There is a possibility that one compact has 20 failed DTFs, and another has no DTF failures. For this report, it is assumed that Compact 10-4 has DTF particles that did not fail during irradiation, and if it is further assumed that all Capsule 10 compacts experienced the same DTF failure rate, then Compact 10-4 might have between 9 and 19 failed DTF particles.

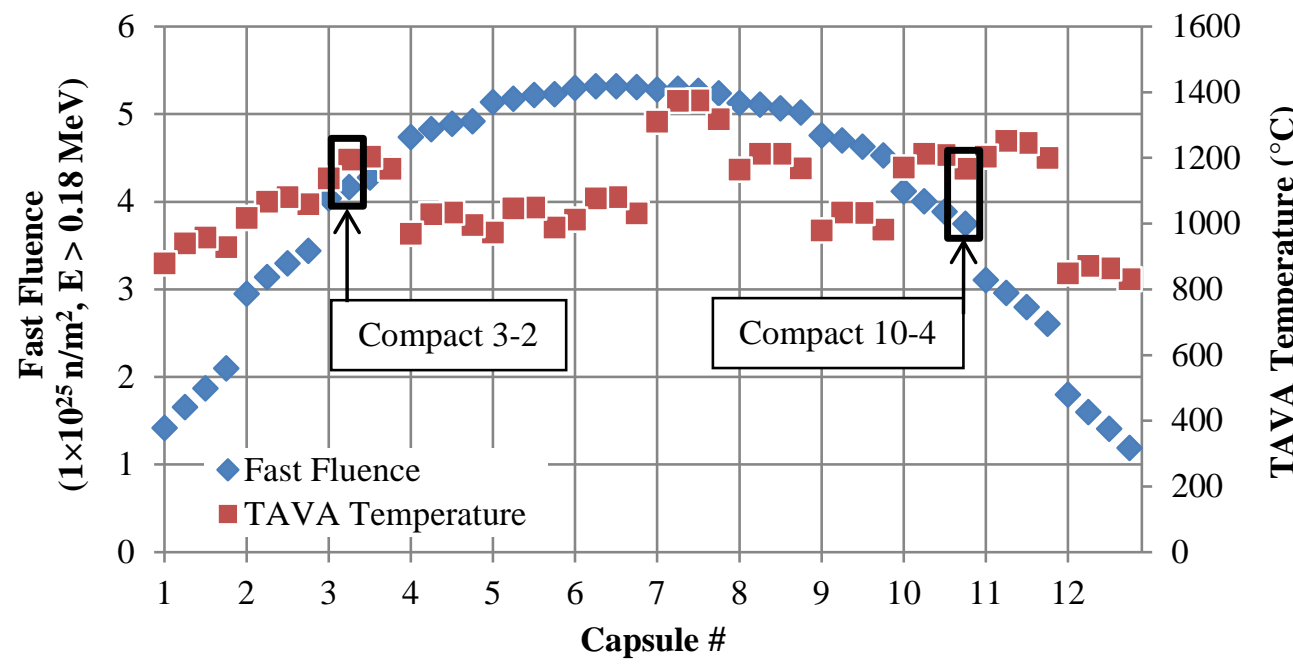

Figure 11. Calculated fast fluence and TAVA temperature for each of the four compacts in each of the twelve AGR-3/4 capsules. Fluences and temperatures from (Hawkes 2016) and (Sterbentz 2015), respectively.

Table 8. Selected fuel-fabrication and irradiation properties for Compact 3-2.

\begin{tabular}{|c|c|}
\hline Compact $^{\mathrm{a}}$ & $3-2$ \\
\hline Fuel Compact Fabrication ID $^{\mathrm{b}}$ & (LEU03-10T-OP2/LEU03-07DTF-OP1)-Z040 \\
\hline Compact Average Burnup (\%FIMA) ${ }^{\mathrm{c}}$ & 12.49 \\
\hline Compact average Fast Fluence $\left(\mathrm{n} / \mathrm{m}^{2}, \mathrm{E}>0.18 \mathrm{MeV}\right)^{\mathrm{c}}$ & $4.17 \times 10^{25}$ \\
\hline TAVA Irradiation Temperature $\left({ }^{\circ} \mathrm{C}\right)^{\mathrm{d}}$ & 1196 \\
\hline TA Peak Irradiation Temperature $\left({ }^{\circ} \mathrm{C}\right)^{\mathrm{e}}$ & 1240 \\
\hline TA Minimum Irradiation Temperature $\left({ }^{\circ} \mathrm{C}\right)^{\mathrm{e}}$ & 1154 \\
\hline \multicolumn{2}{|c|}{$\begin{array}{l}\text { a. X-Y naming convention denotes location in irradiation test train: Capsule-Level (Demkowicz 2017). } \\
\text { b. From (Collin 2015c) and (Hunn, Trammel, and Montgomery, 2011). } \\
\text { c. Based on physics calculations (Sterbentz 2015). FIMA = Fissions per initial metal atom. } \\
\text { d. TAVA = Time-averaged volume averaged temperature determined from thermal calculations (Hawkes 2016). } \\
\text { e. TA = Time-averaged temperature, determined from thermal calculations (Hawkes 2016). }\end{array}$} \\
\hline
\end{tabular}


Table 9. Selected fuel-fabrication and irradiation properties for Compact 10-4.

\begin{tabular}{|l|l|}
\hline Compact $^{\mathrm{a}}$ & $10-4$ \\
\hline Fuel Compact Fabrication ID $^{\mathrm{b}}$ & $($ LEU03-10T-OP2/LEU03-07DTF-OP1)-Z140 \\
\hline Compact Average Burnup $(\% \mathrm{FIMA})^{\mathrm{c}}$ & 11.43 \\
\hline Compact average Fast Fluence $\left(\mathrm{n} / \mathrm{m}^{2}, \mathrm{E}>0.18 \mathrm{MeV}\right)^{\mathrm{c}}$ & $3.75 \times 10^{25}$ \\
\hline TAVA Irradiation Temperature $\left({ }^{\circ} \mathrm{C}\right)^{\mathrm{d}}$ & 1168 \\
\hline TA Peak Irradiation Temperature $\left({ }^{\circ} \mathrm{C}\right)^{\mathrm{e}}$ & 1231 \\
\hline TA Minimum Irradiation Temperature $\left({ }^{\circ} \mathrm{C}\right)^{\mathrm{e}}$ & 1079 \\
\hline $\begin{array}{l}\text { a. X-Y naming convention denotes location in irradiation test train: Capsule-Level (Demkowicz 2017). } \\
\text { b. From }(\text { Collin 2011) and (Hunn, Trammel, and Montgomery, 2011). } \\
\text { c. Based on physics calculations (Sterbentz 2015). } \\
\text { d. TAVA = Time-average volume average temperature determined from thermal calculations (Hawkes 2016). } \\
\text { e. TA = Time-average temperature, determined from thermal calculations (Hawkes 2016). }\end{array}$ \\
\hline
\end{tabular}

Table 10. AGR-3/4 DTF particle failure count in each irradiation capsule. Table from (Collin 2015b) and (Scates 2015).

\begin{tabular}{|c|c|c|c|}
\hline Capsule & Best-estimate & Max & Min \\
\hline 1 & 41 & 81 & 21 \\
\hline 2 & 91 & 168 & 51 \\
\hline 3 & 96 & 146 & 53 \\
\hline 4 & 76 & 100 & 57 \\
\hline 5 & 51 & 92 & 36 \\
\hline 6 & 47 & 53 & 42 \\
\hline 7 & 52 & 75 & 38 \\
\hline 8 & 78 & 129 & 54 \\
\hline 9 & 90 & 99 & 98 \\
\hline 10 & 47 & 75 & 36 \\
\hline 11 & 69 & 92 & 48 \\
\hline 12 & 39 & 49 & 38 \\
\hline
\end{tabular}

\subsection{AGR-3/4 Compact 3-2 $1600^{\circ} \mathrm{C}$ Heating Test}

\subsubsection{Temperature program and condensation plate exchanges}

The heating test of Compact 3-2 was outlined in PLN-5450, "Test Plan for the $1600^{\circ} \mathrm{C}$ Heating Test of AGR-3/4 Compact 3-2,” including pre-test FACS furnace and FGMS preparations, temperature program, condensation plate exchanges, and post-test furnace cleanup runs (Stempien 2017c). PLN-5450 provided options for altering the originally-planned temperature program and plate schedule. These provisions were used to extend the length of the test, increase the test temperature to $1700^{\circ} \mathrm{C}$ at the end of the test, and accomplish additional condensation plate exchanges. Starting at time $t=0$ hours, the furnace was ramped to $300^{\circ} \mathrm{C}$ in 2 hours. After a 2-hour hold at $300^{\circ} \mathrm{C}$, the furnace set point was increased from 300 to $1600^{\circ} \mathrm{C}$ in two hours. From a total elapsed time of 6 hours until 335.5 hours, the furnace was held at $1600^{\circ} \mathrm{C}$. Then at 335.5 hours, the furnace was raised from 1600 to $1700^{\circ} \mathrm{C}$ in one hour, and $1700^{\circ} \mathrm{C}$ was maintained from a total elapsed time of 336.5 hours until 383.7 hours. Note that there is some lag in the furnace thermocouple measuring the temperature in the sample holder and the programmed set point. 
For example, upon the initial heat up to $1600^{\circ} \mathrm{C}$, the furnace thermocouple did not read within $1 \%$ of the $1600^{\circ} \mathrm{C}$ set point (the thermocouple accuracy is approximately $\pm 1 \%$ ) until a total elapsed time of 6.47 hours compared to the temperature set point at $1600^{\circ} \mathrm{C}$ at 6.0 hours. Figure 12 plots the actual temperature profile and the time and temperature of plate changes used during the heating test of Compact 3-2.

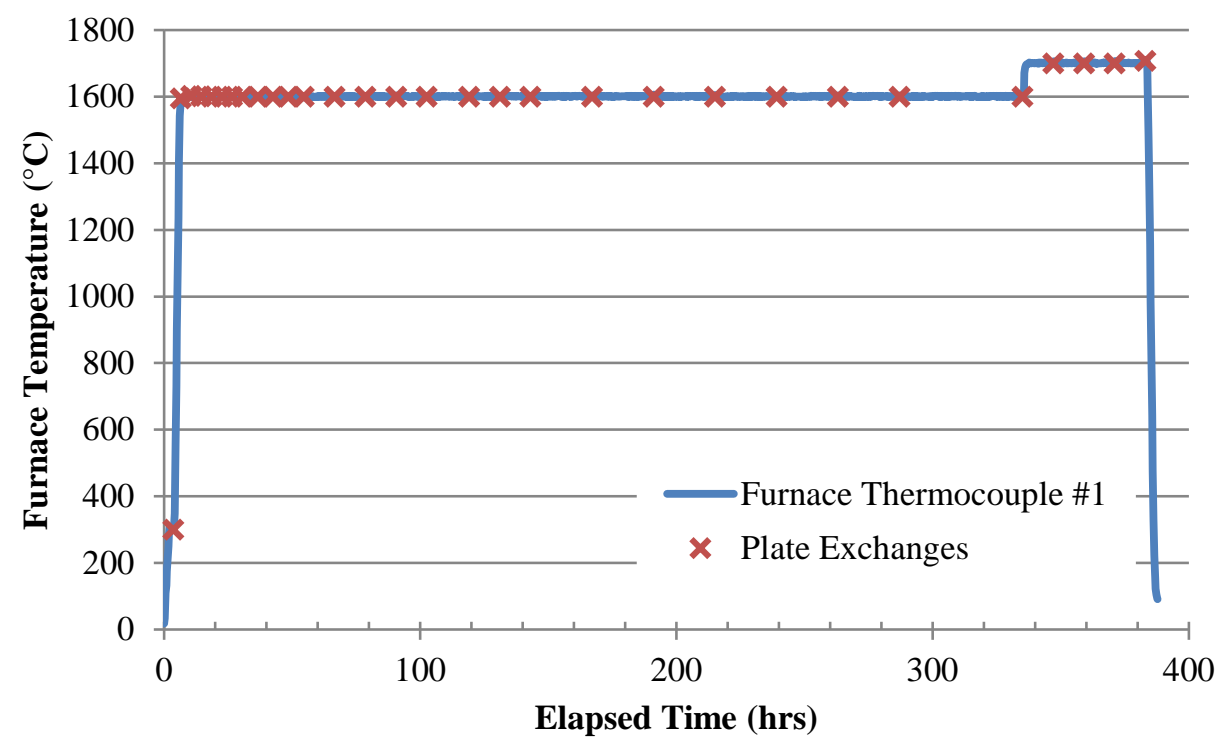

Figure 12. Furnace temperature and time and temperature of condensation plate exchanges for the AGR3/4 Compact 3-2 heating test.

\subsubsection{Measured Fission Product Releases}

After completion of the heating test, each condensation plate was gamma counted at the HOG station. In total, 31 plates were used during the test. The measured gamma activities on each plate were decaycorrected back to the end of the AGR-3/4 irradiation plus one day (EOI+1). The AGR-3/4 irradiation ended on April 12, 2014 at 5:00 AM MT. Where possible, the decay-corrected activities were then divided by pre-determined condensation-plate collection efficiencies for the FACS furnace. (The condensation-plate collection efficiencies used were summarized in Table 6.) To give the measured compact fraction released from the fuel, the decay-corrected and efficiency-corrected activities are then divided by the predicted compact fission product inventory from physics calculations in (Sterbentz 2015). Figure 13 summarizes the cumulative compact fraction of fission products released as a function of the time from the moment the furnace started to heat. Note that Cs-137 and Eu-155 were also measured on the condensation plates, but they are not plotted here. The measured Cs-137 and Cs-134 are generally in good agreement, but due to trace contamination of the longer-lived Cs-137 in the hot cell, Cs-137 readings are usually biased higher than Cs-134. Eu-155 and Eu-154 measurements are generally within $15 \%$ of one another; however, Eu-154 has higher-energy gamma rays that are more consistently measured (with lower error) than Eu-155. Thus, only Eu-154 is plotted to represent europium. The dashed line labeled "Particle" is the compact fraction equivalent to a single particle. Releases less than this dashed line are less than a particle inventory of fission products. The FACS furnace temperature measured at the thermocouple in the sample holder is plotted on the right vertical axis. To better show the observed temperature-dependent behavior, Figure 14 plots the cumulative releases of only Cs-134, Figure 15 plots the cumulative releases of only Eu-154, and Figure 16 plots Kr-85 cumulative releases. Table 11 summarizes the fission product releases for key isotopes (i.e., Ag-110m, Cs-134, Eu-154, Kr 85, and Sb-125) as a fraction of the compact inventory and in terms of the number of particle equivalents. Cesium-137 and Eu-155 were also detected on the condensation plates, but those isotope activities are not 
included here. Table 11 lists releases for the $1600^{\circ} \mathrm{C}$ period, the $1700^{\circ} \mathrm{C}$ period, and the total releases from the start of the test to the end of the test.

In Figure 13, the Ag-110m release fraction appears to be a straight line. Ag-110m was only detected on condensation plates \#2 (inserted in the FACS furnace 30 minutes prior to the ramp from $300^{\circ} \mathrm{C}$ to $1600^{\circ} \mathrm{C}$ and removed 30 minutes after $1600^{\circ} \mathrm{C}$ was reached) and $\# 24$ (inserted at 239 hours and removed at 263 hours when the furnace was at a steady $1600^{\circ} \mathrm{C}$ ). The majority of the total Ag- $110 \mathrm{~m}$ released during the test was collected on plate \#2 (a fraction of 1.22E-3). Little additional Ag was collected on plate \#24, and no additional Ag was measured on plates from the $1700^{\circ} \mathrm{C}$ period. This indicates a rapid release of all transportable Ag early on in the test during the ramp from 300 to $1600^{\circ} \mathrm{C}$. The total fraction of measured Ag- $110 \mathrm{~m}$ release during the test was 1.25E-3, equivalent to 2.36 particle inventories. Postirradiation gamma scanning of Compact 3-2 (after irradiation but prior to heating testing) measured a fraction of 7.1E-2 of the Ag-110m calculated to have been produced in the compact during irradiation was still present in the compact, meaning that approximately $93 \%$ of the Ag-110m produced in the compact during irradiation was released from the compact in-pile. This means that the Ag- $110 \mathrm{~m}$ measured during the heating test was dominated by release from the approximately 1872 driver fuel particles, not the 20 DTF particles. It can be concluded that the majority of the $7 \%$ of the silver remaining in the compact after irradiation was inside intact TRISO driver particles and was not released during the test. It is not possible to determine how much of the relatively small fraction of Ag-110m measured on the condensation plates in the test was from silver retained in the matrix after irradiation and silver that may have been retained in DTF particles after irradiation.

Cesium-134 was measured on all condensation plates. Up to a total elapsed time of 335 hours (30 minutes prior to the ramp from 1600 to $1700^{\circ} \mathrm{C}$ ), a fraction of $1.83 \mathrm{E}-4 \mathrm{Cs}-134$ was released (0.346 particle inventories). During the hold at $1700^{\circ} \mathrm{C}$ (from 336.5 hours until 383.7 hours), a fraction of 3.01E-4 (0.569 particle inventories) was released. Therefore, the Cs-134 release during the relatively short period at $1700^{\circ} \mathrm{C}$ was a factor of 1.6 greater than the release prior to and during the hold at $1600^{\circ} \mathrm{C}$. The difference in the releases between the $1600^{\circ} \mathrm{C}$ period and the $1700^{\circ} \mathrm{C}$ period is more noticeable in Figure 14 than in the Figure 13 summary. The total fraction of Cs-134 released was 4.84E-4 (0.915 particle equivalents) at the time the test was ended. For comparison, the fractional release of Cs-134 from $1600^{\circ} \mathrm{C}$ safety testing of AGR-1 Compact 4-3-3 for 300 hours was 6.8E-7 (Demkowicz et al. 2015b). The fact that a higher fraction of Cs- 134 was detected from the $1600^{\circ} \mathrm{C}$ portion of the test of AGR-3/4 Compact 3-2 suggests that the DTF particles could have contributed to this elevated release. Some Cs could have been retained in the DTF kernels after irradiation, and that Cs could have been released from the compact during heating testing. Some Cs that escaped the DTF particles during the irradiation could have been held up in the compact matrix, and that Cs would be readily released during the heating test.

AGR-1 safety test data and post-test compact analysis (including gamma counting of individual particles that experienced $\mathrm{SiC}$ failure) indicate that the level of cesium release from particles that experience $\mathrm{SiC}$ failure at $1600-1800^{\circ} \mathrm{C}$ can vary significantly. Individual particle cesium release ranged from approximately 20 to 95\% (Demkowicz et al. 2015a). It was thought that the pyrocarbon layer applied to the 20 DTF particles in AGR-3/4 Compact 3-2 would not substantially retain Cs, even if it remained intact. The thought was that intact DTF particles would behave like TRISO particles with SiClayer failures (releasing substantial Cs, but retaining fission gases), and failed DTF particles would behave like TRISO particles with failed TRISO coatings (releasing both Cs and fission gases). The fact that only 0.915 particles worth of Cs was measured from this $1600-1700^{\circ} \mathrm{C}$ heating test suggests two explanations: (1) DTF particles behave like particles with SiC layer failures described earlier in this paragraph, and a significant portion of Cs in the DTF particles was released in-pile during irradiation in ATR, so that little Cs remained in the DTF particles for release during heating, or (2) significant Cs was retained in the DTF kernels during the heating test. A combination of both explanations is possible. To confirm explanation \#1, the AGR-3/4 fission product mass balance throughout AGR-3/4 Capsule 3 must be quantified. To confirm explanation \#2, destructive examinations of Compact 3-2 must be performed to 
quantify any Cs inventory remaining in various portions of the fuel. Work on the AGR-3/4 mass balance and Compact 3-2 destructive exam is in progress.

Eu-154 releases are steadier throughout the test compared to Ag-110m and Cs-134. This may be due to Eu that was released to and retained in the compact matrix during irradiation, and release from the DTF particles may also be contributing. Ongoing as-irradiated compact radial deconsolidations will be used to determine the inventory of Eu-154 in the compact outside of the fuel particle SiC layer (Stempien 2017d). AGR-3/4 Compact 3-3 has been radially deconsolidated, and the fission product analyses are in-progress. Comparing the Eu-154 released during the Compact 3-2 heating test to that retained in the matrix of the as-irradiated AGR-3/4 Compact 3-3 could be used to infer the Eu-154 inventory retained in the DTF particles. A complication is that diffusive release of Eu through intact driver particles may contribute to measured Eu-154, particularly at temperatures $>1600^{\circ} \mathrm{C}$. Figure 15 (and Figure 13) show a notable increase in the released Eu-154 fraction when the temperature was raised to $1700^{\circ} \mathrm{C}$. From the beginning of the test to the end of the period at $1600^{\circ} \mathrm{C}$, a fraction of $5.58 \mathrm{E}-3$ was released (10.57 particle equivalents). An additional fraction of $2.34 \mathrm{E}-3$ (4.42 particles) was released between the ramp to $1700^{\circ} \mathrm{C}$ and the completion of the test. In total, a fraction of 7.92E-3 (14.99 particle equivalents) of Eu-154 was released during the test.

The shape of the Sb-125 cumulative releases versus time is similar to that of Cs-134; however, the fractional amount of Sb-125 released is higher than for Cs-134. From $t=0$ up to the ramp from 1600 to $1700^{\circ} \mathrm{C}$ at 335 hours, a fraction of 5.34E-3 (10.11 particle inventories) was released. During the period of time at $1700^{\circ} \mathrm{C}$, an additional $0.322 \mathrm{E}-3$ ( 0.61 particle inventories) was released. A total Sb- 125 fraction of 5.67E-3 (10.72 particle inventories) was released during the test.

The fission gas Kr-85 was collected in cold traps in the FGMS, and gamma counting of these traps ran continuously during the test. The fractional release of Kr-85 tends to follow that of Cs-134 (see Figure 13); however, very little additional Kr-85 was released after increasing the test temperature to $1700^{\circ} \mathrm{C}$ (see Figure 13 and Figure 16). Assuming that krypton would be rapidly released from exposed kernels at these temperatures (a reasonable assumption based on previous TRISO heating tests), this indicates that that majority of the Kr-85 had been released from the DTF particles during irradiation. It also suggests that if any DTF particles were intact at the start of this heating test (unlikely based on the data in Table 9), they did not fail at any point during this heating test. From the initiation of the test up to the end of the period at $1600^{\circ} \mathrm{C}$, a fraction of $1.64 \mathrm{E}-4$ was released ( 0.309 particle equivalents). During the period at $1700^{\circ} \mathrm{C}$ and the ramp down at the completion of the test, a fraction of $0.282 \mathrm{E}-4(0.053$ particle inventories) Kr-85 was released. A total of 1.92E-4 (0.362 particle equivalents) Kr-85 was released during the test. In comparison, during $1600^{\circ} \mathrm{C}$ testing of AGR-1 Compacts 6-4-1 and 4-3-3, fractional Kr-85 releases were lower, at 1.9E-6 and 1.4E-6, respectively (Demkowicz et al. 2015b). Given that the fraction of Kr-85 released from AGR-3/4 Compact 3-2 is two orders of magnitude greater than for AGR-1 Compacts 6-4-1 and 4-3-3, this indicates that the majority of the measured Kr-85 from AGR-3/4 Compact 3-2 was due to release of the relatively small amount of $\mathrm{Kr}-85$ retained in the failed DTF particle fuel kernels. 


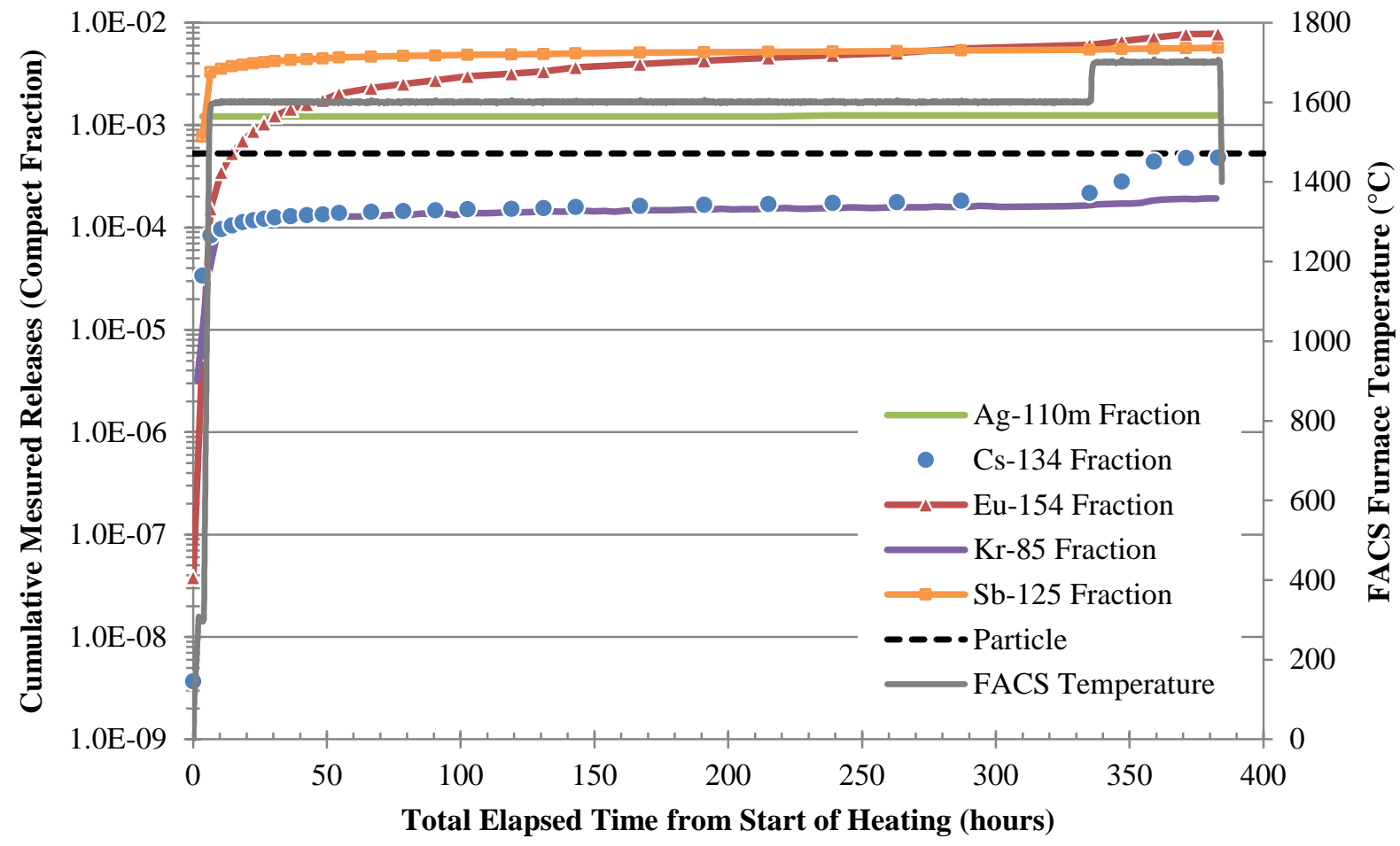

Figure 13. Total compact fractions of fission products measured from condensation plates from the heating test of Compact 3-2. FACS furnace temperature is also plotted along with the compact fraction equivalent to one particle inventory (5.29E-4).

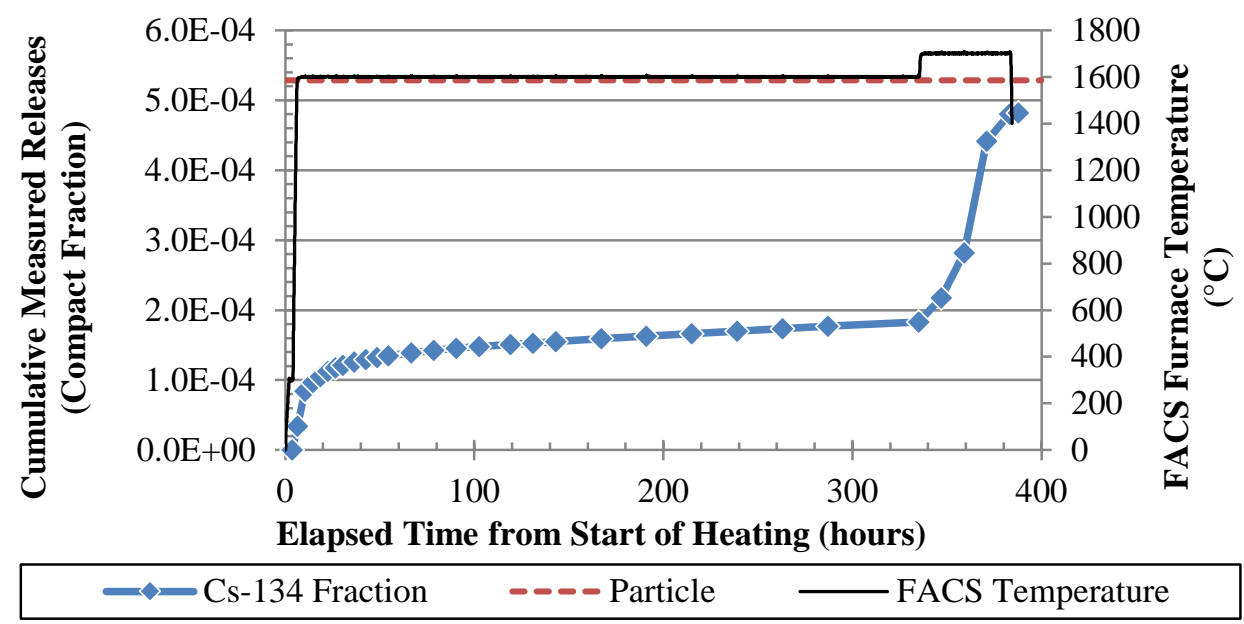

Figure 14. Cs-134 cumulative releases versus time. 


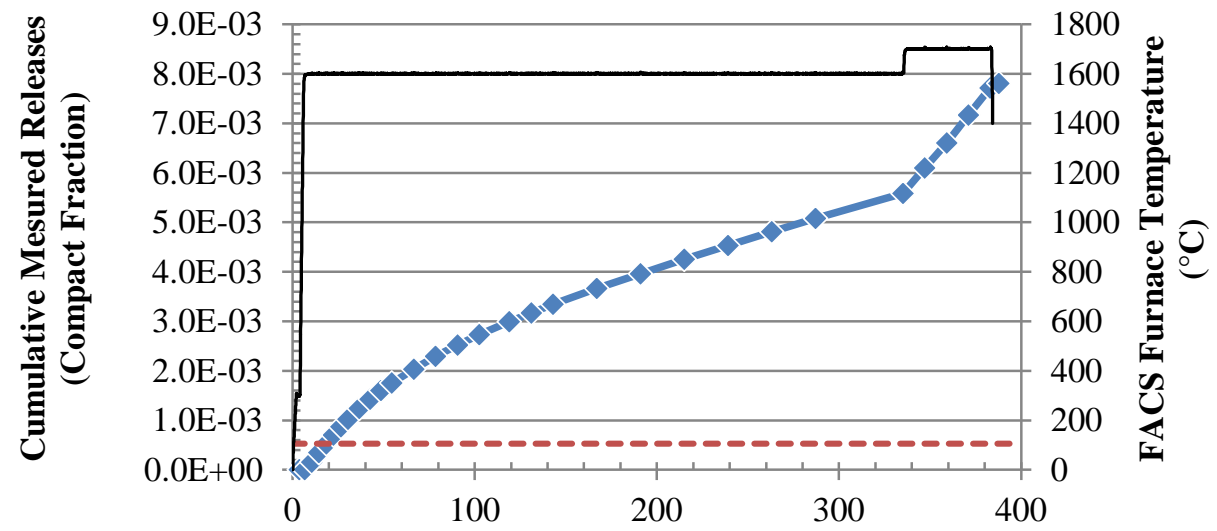

Elapsed Time from Start of Heating (hours)

$\because-$ Eu-154 Fraction $\quad-\infty-$ Particle $\quad$ FACS Temperature

Figure 15. Eu-154 cumulative releases versus time.

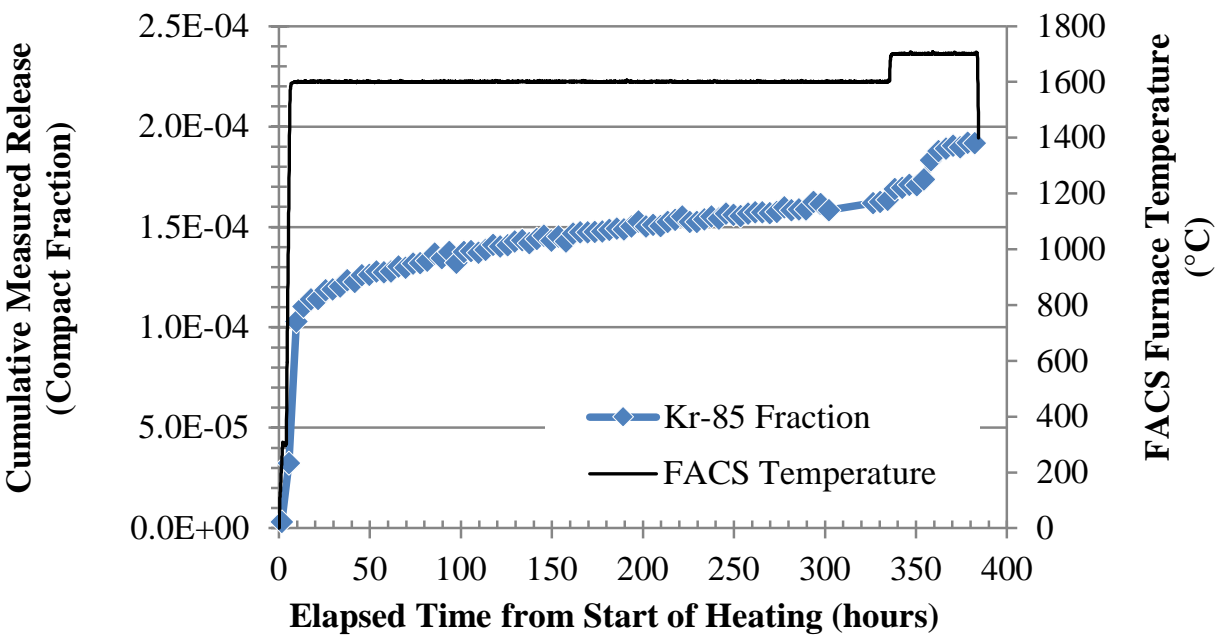

Figure 16. Kr-85 cumulative releases versus time.

Table 11. Total fission-product release summary for AGR-3/4 Compact 3-2.

\begin{tabular}{|l|l|l|l|l|l|l|}
\hline \multirow{2}{*}{} & \multicolumn{3}{|l|}{$\begin{array}{l}\text { Release from start of test to } \\
\text { end of } 1600^{\circ} \mathrm{C} \text { period }\end{array}$} & \multicolumn{2}{l|}{$\begin{array}{l}\text { Release from ramp to } \\
1700^{\circ} \mathrm{C} \text { and test completion }\end{array}$} & \multicolumn{2}{l|}{ Total Release } \\
\cline { 2 - 7 } & Fraction & Particle & Fraction & Particle & Fraction & Particle \\
\hline Ag-110m & $1.25 \mathrm{E}-3$ & 2.36 & N/D & N/D & $1.25 \mathrm{E}-3$ & 2.36 \\
\hline Cs-134 & $1.83 \mathrm{E}-4$ & 0.346 & $3.01 \mathrm{E}-4$ & 0.569 & $4.84 \mathrm{E}-4$ & 0.915 \\
\hline Eu-154 & $5.58 \mathrm{E}-3$ & 10.6 & $2.34 \mathrm{E}-3$ & 4.42 & $7.92 \mathrm{E}-3$ & 15.0 \\
\hline Kr-85 & $1.64 \mathrm{E}-4$ & 0.309 & $0.282 \mathrm{E}-4$ & 0.053 & $1.92 \mathrm{E}-4$ & 0.362 \\
\hline Sb-125 & $5.34 \mathrm{E}-3$ & 10.1 & $0.322 \mathrm{E}-3$ & 0.610 & $5.67 \mathrm{E}-3$ & 10.7 \\
\hline Sr-90 & N/A & N/A & N/A & N/A & N/A & N/A \\
\hline N/A: not available for this report. Sr-90 dissolution, separation, and gas proportional counting is in-progress. \\
\hline
\end{tabular}




\subsubsection{Fission product release rates}

Release rates for the condensable, metallic fission products are summarized in Figure 17. Release rates were calculated by taking the compact fractional inventory measured on each condensation plate and dividing by residence time for each plate in the FACS furnace. The rates were then plotted at the middle of the residence time for each plate (e.g., if a plate was in the FACS furnace from hour 5 until hour 10, that plate's release rate was plotted at 7.5 hours). Figure 18 and Figure 19 use linear plots to show the cumulative releases for $\mathrm{Kr}-85$, and trend lines were fit to different portions of the $\mathrm{Kr}-85$ data to give average release rates over certain periods of the test.

Silver was only detected on two plates: plate \#2 and plate \#24. Plate \#2 was inserted in the FACS furnace 30 minutes prior to the ramp from $300^{\circ} \mathrm{C}$ to $1600^{\circ} \mathrm{C}$ and removed 30 minutes after $1600^{\circ} \mathrm{C}$ was reached. Thus, plate \#2 spent the majority of its time in the FACS furnace during the two-hour ramp from $300^{\circ} \mathrm{C}$ to $1600^{\circ} \mathrm{C}$. Over this total period of 3 hours, the Ag- $110 \mathrm{~m}$ release rate was 4.07E-4 hr ${ }^{-1}$. Plate \#24 was inserted at 239 hours and removed at 263 hours when the furnace was at a steady $1600^{\circ} \mathrm{C}$. Over this period of time, the release rate was much lower, 1.34E-6 hr-1. Prior heating tests of irradiated AGR fuel (Demkowicz et al. 2015b) have shown that Ag release rates are initially high, as Ag released to and retained in the compact matrix during irradiation is released upon heating. Furthermore, there is a temperature region from approximately 1100 to $1300^{\circ} \mathrm{C}$ where $\mathrm{Ag}$ is more mobile than at higher and lower temperatures (Hunn et al. 2015). These two early-test effects explain the measured rate of Ag-110m release on plate \#2.

After the matrix inventory of Ag-110m has been released, the release rate is much lower and is limited by slow diffusion of Ag from intact fuel particles. Precision gamma scanning (PGS) was used to measure the inventory of gamma-emitting fission products in Compact 3-2 after irradiation, and the M/C of Ag-110m was 0.071, indicating that Compact 3-2 retained approximately 7\% of the Ag produced in it during irradiation. It is unlikely that the DTF particles retained significant Ag, and after over 200 hours at $1600^{\circ} \mathrm{C}$, the compact matrix would have been largely emptied of any retained Ag. Thus, it is reasonable that the Ag-110m release rate measured from plate \#24 was much lower. The rate of $1.34 \mathrm{E}-6 \mathrm{hr}^{-1}$ is similar to the rates measured from $1600^{\circ} \mathrm{C}$ safety testing of irradiated AGR-1 Compacts 4-3-3 and 6-4-1 (Demkowicz et al. 2015b).

As shown in Figure 16, there can be point-to-point variations in the Kr-85 activity measured in the FGMS cold trap such that the value for one point may be less than the value in the previous data point. This makes plots of the point-to-point Kr-85 release rate difficult to interpret. Thus, the cumulative Kr-85 release was plotted, and linear fits were used to determine release rates. Figure 18 shows the measured $\mathrm{Kr}-85$ amounts (expressed as decay-corrected fractions of a compact inventory) detected throughout the test. Three linear fits are shown in Figure 18, giving Kr-85 release rates of $1.246 \mathrm{E}-5 \mathrm{hr}^{-1}$ from 0 to 9.6 hours, 3.093E-7 hr-1 from 9.6 to 97.6 hours, and 1.105E-7 $\mathrm{hr}^{-1}$ from 101.6 to 334.4 hours. The Kr-85 amounts measured during the period of time at $1700^{\circ} \mathrm{C}$ are plotted in Figure 19, and three trend lines were fit for this $1700^{\circ} \mathrm{C}$ period. The first trend line was fit to the $\mathrm{Kr}-85$ data from 338 to 354 hours and gives a rate of $2.760 \mathrm{E}-7 \mathrm{hr}^{-1}$, more than double the average rate from the preceding period of $1600^{\circ} \mathrm{C}$ operation. In the second segment at $1700^{\circ} \mathrm{C}$ (from 350 to $362 \mathrm{hrs),} \mathrm{the} \mathrm{Kr}-85$ release rate was $1.511 \mathrm{E}-6 \mathrm{hr}^{-1}$, about a factor of 10 less than the rate detected during the initial heat up to $1600^{\circ} \mathrm{C}$. During the final period of time at $1700^{\circ} \mathrm{C}$ (from 358 to $382.4 \mathrm{hrs}$ ), the $\mathrm{Kr}-85$ release rate was $3.066 \mathrm{E}-7 \mathrm{hr}^{-1}$, almost identical to the rate early on in the hold at $1600^{\circ} \mathrm{C}$ (from 9.6 to 97.6 hrs in Figure 18). These Kr-85 release rates are generally greater than those observed at $1600^{\circ} \mathrm{C}$ from AGR-1 safety testing (where $\mathrm{Kr}-85$ release rates were on the order of $1 \mathrm{E}-9$ ) and $1700^{\circ} \mathrm{C}$ AGR-1 safety testing where $\mathrm{Kr}-85$ release rates are generally on the order of 1E-8. In the $1800^{\circ} \mathrm{C}$ safety test of AGR-1 Compact 3-2-3, where one or two SiC layer failures occurred, the $\mathrm{Kr}-85$ release rate was $1.27 \mathrm{E}-7 \mathrm{hr}^{-1}$, comparable to the $\mathrm{Kr}-85$ release rates measured for much of this test of AGR-3/4 Compact 3-2. 


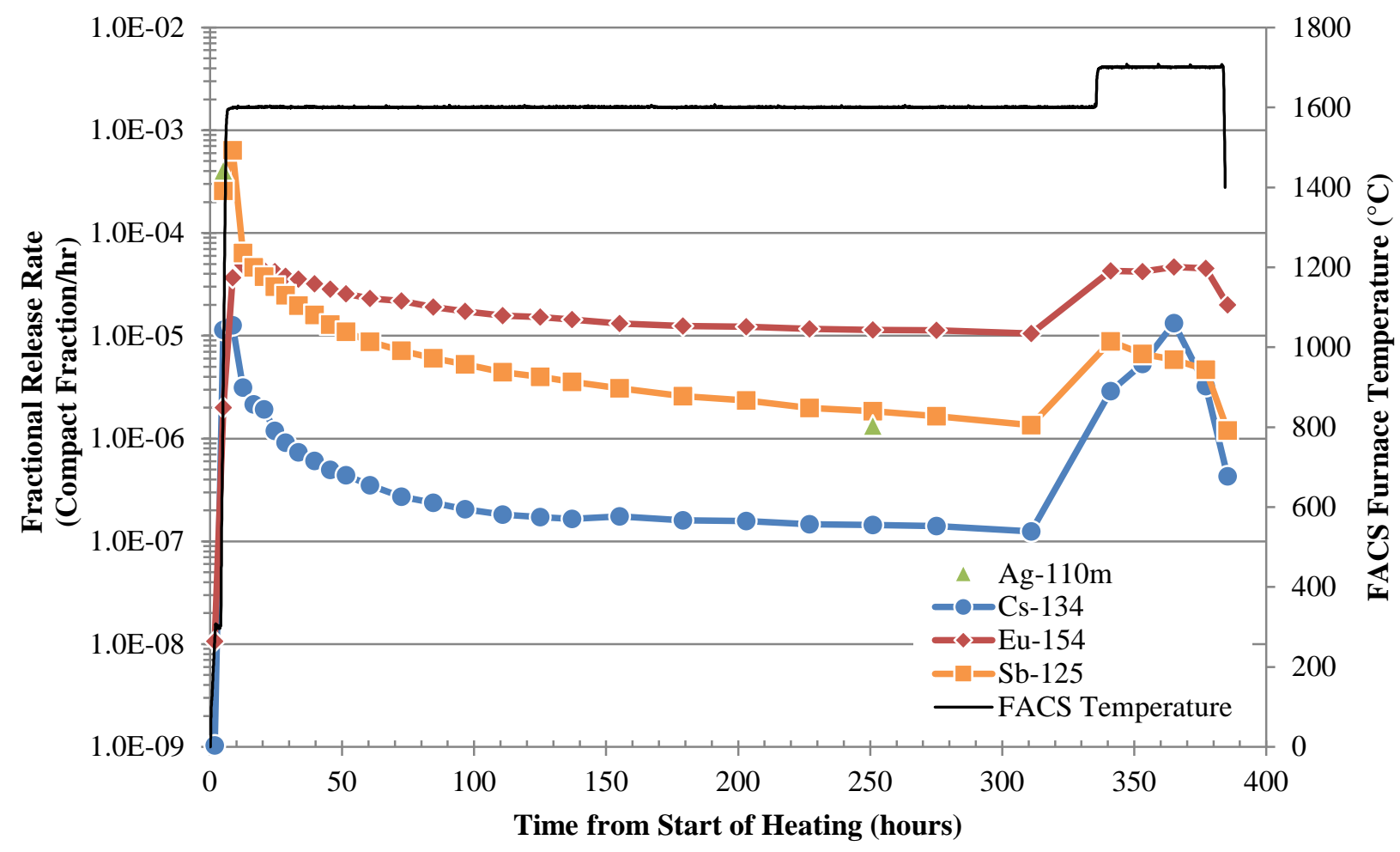

Figure 17. Summary of condensable fission-product release rates.

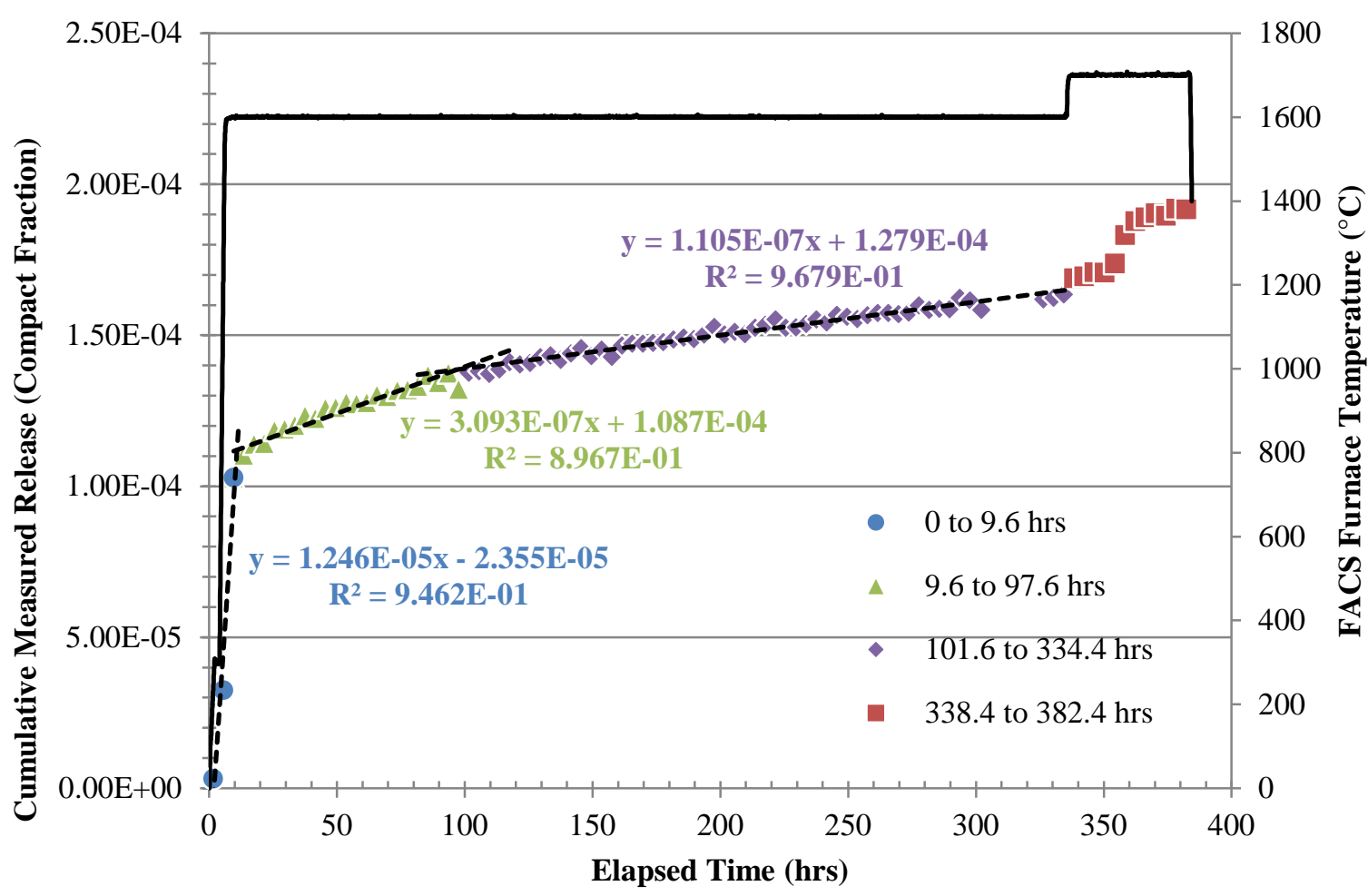

Figure 18. Kr-85 cumulative releases and trend lines giving average release rates over the test period at $1600^{\circ} \mathrm{C}$ and including start-up to 334 hours. 


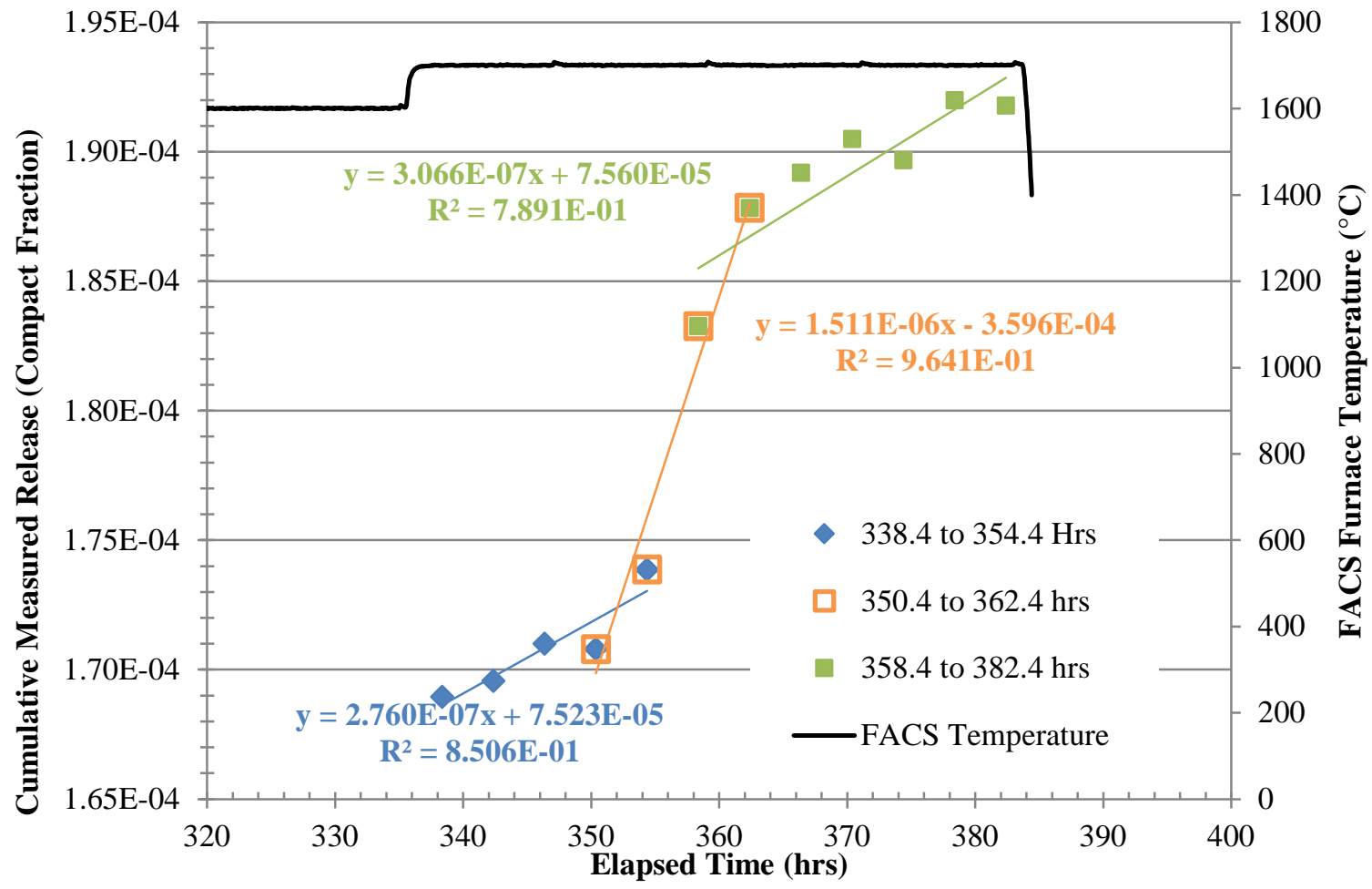

Figure 19. $\mathrm{Kr}-85$ cumulative releases and trend lines giving release rates $\left(\mathrm{hr}^{-1}\right)$ during the $1700^{\circ} \mathrm{C}$ period of the test.

\subsection{AGR-3/4 Compact $10-41400^{\circ} \mathrm{C}$ Heating Test}

\subsubsection{Temperature program and condensation plate exchanges}

The heating test of Compact 10-4 was outlined in PLN-5518, “Test Plan for the $1400^{\circ} \mathrm{C}$ Heating Test of AGR-3/4 Compact 10-4,” and includes pre-test FACS furnace and FGMS preparations, FACS temperature program, condensation plate exchange schedule, and post-test furnace cleanup runs (Stempien 2017e). PLN-5518 provided options for altering the originally planned temperature program and plate schedule. Starting at time $\mathrm{t}=0$ hours, the furnace was ramped to $300^{\circ} \mathrm{C}$ in 2 hours. After a 2hour hold at $300^{\circ} \mathrm{C}$, the furnace set point was increased from 300 to $1400^{\circ} \mathrm{C}$ in two hours. From a total elapsed time of 6 hours until 306 hours, the furnace was held at $1400^{\circ} \mathrm{C}$. Then at 306 hours (after 300 total hours at $1400^{\circ} \mathrm{C}$ ), the furnace was allowed to cool (reaching less than $200^{\circ} \mathrm{C}$ in less than 3 hours). Note that there is slight lag in the temperature measured by the furnace thermocouple in the sample holder and the programmed set point. For example, upon the initial heat up to $1400^{\circ} \mathrm{C}$, the furnace thermocouple did not read within $1 \%$ of the $1400^{\circ} \mathrm{C}$ set point (the thermocouple accuracy is approximately $\pm 1 \%$ ) until a total elapsed time of 6.25 hours compared to the temperature set point at $1400^{\circ} \mathrm{C}$ at 6.0 hours. Figure 20 plots the temperature program and the actual times and temperatures of the plate exchanges carried out during the heating test of Compact 10-4. 


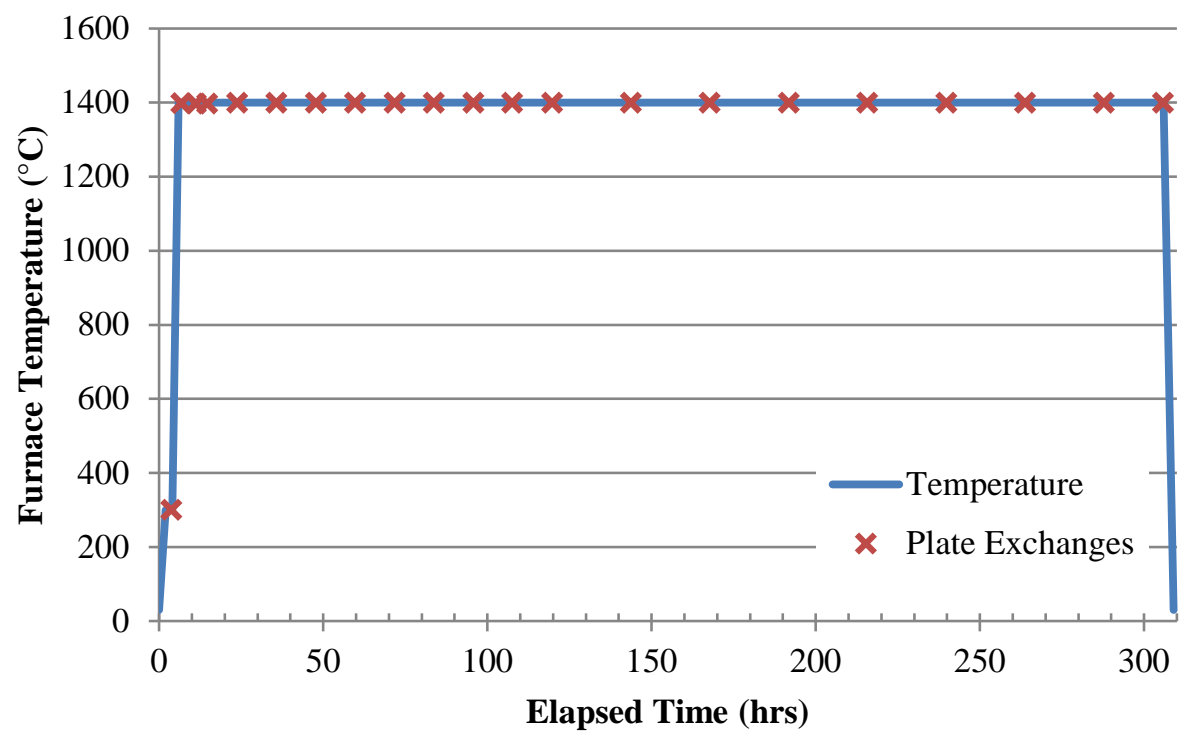

Figure 20. Temperature program and actual time and temperature of condensation-plate exchanges for the AGR-3/4 Compact 10-4 heating test.

\subsubsection{Measured Fission Product Releases}

After completion of the heating test, each condensation plate was gamma counted at the HOG station. In total, 22 plates were used during the test. The measured gamma activities on each plate were decay-corrected back to the end of the AGR-3/4 irradiation plus one day (EOI+1). The AGR-3/4 irradiation ended on April 12, 2014 at 5:00 AM MT. Decay-corrected activities were then divided by pre-determined condensation plate collection efficiencies in the FACS furnace (summarized in Table 6). To give the measured compact fraction released from the fuel, the decay-corrected and efficiencycorrected activities are then divided by the predicted compact fission-product inventory from physics calculations in (Sterbentz 2015). The efficiencies listed in Table 6 were measured at $1600^{\circ} \mathrm{C}$; however, the heating test of AGR-3/4 Compact $10-4$ was conducted at $1400^{\circ} \mathrm{C}$, where the condensation plate collection efficiencies will be different. Future FACS furnace efficiency testing at $1400^{\circ} \mathrm{C}$ will be performed in order to give new efficiencies that can be used to update the data reported here.

Figure 21 summarizes the cumulative compact fraction of fission products released as a function of the time from the moment the furnace started to heat until the end of the test. Note that Cs-137 and Eu-155 were also measured on the condensation plates, but they are not plotted here. The measured Cs-137 and Cs-134 are generally in good agreement, but due to trace contamination of the longer-lived Cs-137 in the hot cell, Cs-137 readings are usually biased higher than Cs-134. Europium-154 was measured on the majority of the condensation plates; however, Eu-155 was only detected on a couple of plates. Europium-154 has higher-energy gamma rays that are more consistently measured than Eu-155; therefore, only Eu-154 is plotted to represent europium. The dashed line labeled "Particle" is the compact fractional inventory equivalent to a single particle. Releases less than this dashed line are less than a particle inventory of fission products. The FACS furnace temperature measured at the thermocouple in the sample holder is plotted on the right vertical axis. Table 12 summarizes fission-product releases for key isotopes (i.e., Ag-110m, Cs-134, Eu-154, Kr-85, and Sb-125) as a fraction of the compact inventory and in terms of the number of particle equivalents. Table 12 lists the total releases from the start of the test to the end of the test. 
The total fraction of measured Ag-110m release during the test was 4.40E-3, equivalent to 8.33 particle inventories. In Figure 21, the Ag-110m release fraction appears as a nearly straight line. This is because the second condensation plate (which resided in the furnace from 3.7 to 6.7 hours) collected an order of a magnitude more Ag-110m than any other single plate in the test. A compact fraction of $2.45 \mathrm{E}-3$ was collected on the second plate at 6.7 hours, and only an additional 1.95E-3 of Ag-110m was collected over the remaining approximately 300 hours of the test. This indicates a rapid release of all transportable Ag early on in the test. Post-irradiation gamma scanning of Compact 10-4 (after irradiation but prior to FACS heating testing) measured that $3.9 \mathrm{E}-2$ of the Ag- $110 \mathrm{~m}$ calculated to have been produced in the compact during irradiation was still present in the compact, meaning that approximately $96 \%$ of the Ag- $110 \mathrm{~m}$ produced in the compact during irradiation was released from the compact in-pile. This means that the Ag$110 \mathrm{~m}$ measured during the heating test was dominated by release from the approximately 1872 driver fuel particles, not the 20 DTF particles. It is assumed that some of the Ag remaining in the compact after irradiation would have been retained in the TRISO particles, and some would have been retained in the compact matrix. The 2.45E-3 measured early on in the test (after 6.7 hours) is most-likely to be from Ag retained in the compact matrix. DTF particles could also have contributed to this; however, there is no way to distinguish Ag contributed from DTF particles from that contributed from the compact matrix. The additional 1.95E-3 released after 6.7 hours could be from additional release of Ag retained in the matrix, but the lower release rate (discussed below) could suggest that this is release from particles.

The total fraction of Cs-134 released was 7.51E-5 (0.142 particle equivalents). With intact fuel particles, the total Cs release from $1600^{\circ} \mathrm{C}$ safety testing of AGR-1 Compact 4-3-3 for 300 hours was 6.8E-7 (Demkowicz et al. 2015b). Based on this experience from AGR-1 heating tests, Cs release from the intact driver particles in AGR-3/4 Compact 10-4 was not expected in any significant quantity. The fact that a higher fraction of Cs-134 was detected from this $1400^{\circ} \mathrm{C}$ test of AGR-3/4 Compact 10-4 suggests that the DTF particles could have contributed to this elevated release. Some Cs could have been retained in the DTF kernels after irradiation, and that Cs could have been released from the compact during heating testing. Some Cs that escaped the DTF particles during the irradiation could have been held up in the compact matrix, and that Cs would be readily released during the heating test.

AGR-1 safety test data and post-test compact analysis (including gamma counting of individual particles that experienced $\mathrm{SiC}$ failure) indicate that the level of cesium release from particles that experience $\mathrm{SiC}$ failure at $1600-1800^{\circ} \mathrm{C}$ can vary significantly. Individual-particle cesium release ranged from approximately 20 to 95\% (Demkowicz et al. 2015a). It was thought that the pyrocarbon layer applied to the 20 DTF particles in AGR-3/4 Compact 10-4 would not substantially retain Cs, even if it remained intact. The thought was that intact DTF particles would behave like TRISO particles with SiC layer failures (releasing substantial Cs, but retaining fission gases), and failed DTF particles would behave like TRISO particles with failed TRISO coatings (releasing both Cs and fission gases).The fact that only 0.142 particles worth of Cs was measured from this $1400^{\circ} \mathrm{C}$ heating test suggests two explanations: (1) DTF particles behave like particles with SiC layer failures described earlier in this paragraph, a significant portion of Cs in the DTF particles was released in-pile during irradiation in ATR, and little Cs remained in the DTF particles for release during heating, or (2) significant Cs was retained in the DTF kernels during the heating test. A combination of both explanations is possible. To confirm explanation \#1, the AGR-3/4 fission product mass balance throughout AGR-3/4 Capsule 10 must be quantified. To confirm explanation \#2, destructive examinations of Compact 10-4 must be performed to quantify any Cs inventory remaining in various portions of the fuel. Work on the AGR-3/4 mass balance and Compact 10-4 destructive exam is in progress.

In total, a fraction of 1.31E-5 (0.0248 particle equivalents) of Eu-154 was released during the test. Eu-154 releases are more gradual throughout the test compared to Ag-110m and Cs-134. This may be due to release of Eu that was released to and retained in the compact matrix during irradiation; release from DTF particles could also be contributing. Note that only two of the first seven condensation plates had measurable Eu-154, giving the stepped appearance of the Eu-154 data prior to 50 hours in Figure 21. 
Compact radial deconsolidation will be used to determine the inventory of Eu-154 remaining in the compact outside of the fuel particle SiC layer (Stempien 2017d).

The shape of the Sb-125 cumulative releases versus time is similar to that of Cs-134; however, the fractional amount of Sb-125 released is higher than for Cs-134 and similar to that of Ag-110m. Silver and Sb were the only elements to be released in quantities exceeding the inventory in a single particle. Total Sb-125 releases were a compact fraction of 3.84E-3, equivalent to 7.24 particle inventories.

The fission gas Kr-85 was collected in cold traps in the FGMS, and gamma counting of these traps ran continuously during the test. In Figure 21, the fractional release of $\mathrm{Kr}-85$ tends to follow that of Cs-134. A total fraction of 1.53E-4 (0.290 particle equivalents) was released from AGR-3/4 Compact 10-4, similar to 1.64E-4 released from the $1600^{\circ} \mathrm{C}$ test of AGR-3/4 Compact 3-2. For additional comparisons, during $1600^{\circ} \mathrm{C}$ testing of AGR-1 Compacts 6-4-1 and 4-3-3, fractional $\mathrm{Kr}-85$ releases were lower at 1.9E-6 and 1.4E-6 respectively (Demkowicz et al. 2015b). Given that the fraction of Kr-85 released from AGR-3/4 Compact 10-4 is two orders of magnitude greater than from AGR-1 Compacts 6-4-1 and 4-3-3(which were tested at higher temperatures), this indicates that the majority of the measured Kr-85 from AGR-3/4 Compact 10-4 was due to release of Kr-85 retained in the failed DTF particle fuel kernels. Recall from Section 3.1 that between 9 and 19 failed DTF particles may have been present in Compact 10-4 after irradiation. Section 3.1 also discussed the uncertainty with that estimated number of DTF failures. Destructive analysis of Compact 10-4 can be used to determine the number of failed DTFs in the compact after the heating test. Since only $29 \%$ of a single particle inventory of $\mathrm{Kr}-85$ was measured, it is possible that any DTF particles that might have remained intact after irradiation and prior to the heating test did not fail during heating and/or did not substantially contribute to the measured $\mathrm{Kr}-85$.

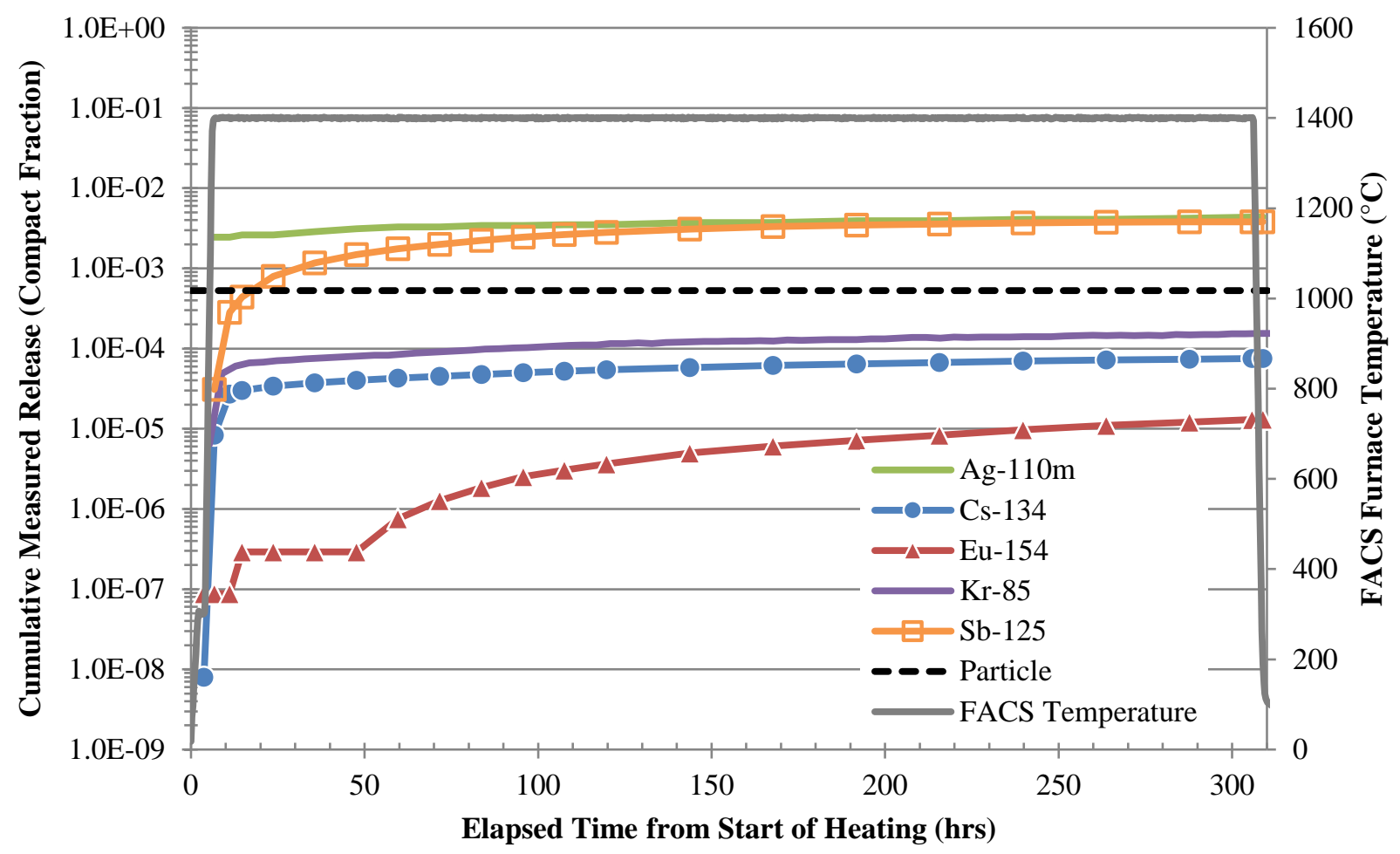

Figure 21. Total compact fractions of fission products measured from condensation plates from the heating test of AGR-3/4 Compact 10-4. FACS furnace temperature is also plotted along with the compact fraction equivalent to one particle inventory $(5.29 \mathrm{E}-4)$. 
Table 12. Summary of total fission product release from AGR-3/4 Compact 10-4.

\begin{tabular}{|l|c|c|}
\hline \multirow{2}{*}{} & \multicolumn{2}{|c|}{ Total Release } \\
\cline { 2 - 3 } & Fraction & Particle Equivalent \\
\hline Ag-110m & $4.40 \mathrm{E}-3$ & 8.33 \\
\hline Cs-134 & $7.51 \mathrm{E}-5$ & 0.141 \\
\hline Eu-154 & $1.31 \mathrm{E}-5$ & 0.0248 \\
\hline Kr-85 & $1.53 \mathrm{E}-4$ & 0.290 \\
\hline Sb-125 & $3.82 \mathrm{E}-3$ & 7.24 \\
\hline Sr-90 & N/A & N/A \\
\hline N/A: not available for this report. Sr-90 dissolution, separation, and gas proportional counting is in-progress. \\
\hline
\end{tabular}

\subsubsection{Fission product release rates}

Release rates for the condensable, metallic fission products are summarized in Figure 22 where the release rates are plotted at the middle of the FACS furnace residence time for each condensation plate. Figure 23 and Figure 24 use linear plots to show the cumulative releases for $\mathrm{Kr}$-85, and trend lines were fit to different portions of the Kr-85 data to give average release rates over certain periods of the test.

The Ag release rate was highest (at $8.17 \mathrm{E}-4 \mathrm{hr}^{-1}$ ) very early in the test, during the three hour period of time starting 30 minutes prior to the start of the ramp from 300 to $1400^{\circ} \mathrm{C}$ and ending 30 minutes after $1400^{\circ} \mathrm{C}$ was reached. Prior heating tests of irradiated AGR fuel (Demkowicz et al. 2015b) have shown that Ag release rates are initially high as Ag released to and retained in the compact matrix during irradiation is released upon heating. Furthermore, there is a temperature region from approximately 1100 to $1300^{\circ} \mathrm{C}$ where $\mathrm{Ag}$ is more mobile than at higher and lower temperatures (Hunn et al. 2015). By approximately 100 hours, the Ag-110m release rate had decreased to about $6 \mathrm{E}-6 \mathrm{hr}^{-1}$. This suggests that the matrix inventory of Ag-110m was depleted over the first 100 hours of the test, and then the rate becomes limited by slow diffusion of Ag from intact fuel particles. This rate (6E-6 hr-1) is comparable to the Ag release rates measured in the final 100 to 150 hours of the 300 -hour $1600^{\circ} \mathrm{C}$ heating tests of AGR-1 Compacts 4-3-3 and 6-4-1. It is also consistent with the Ag rate data collected during the AGR-1 Compact 4-2-2 multi-temperature test (Hunn et al. 2015). In that test, the rate at $1450^{\circ} \mathrm{C}$ was approximately $1 \mathrm{E}-6 \mathrm{hr}^{-1}$, and the rate at $1300^{\circ} \mathrm{C}$ peaked at approximately $2 \mathrm{E}-5 \mathrm{hr}^{-1}$.

The Sb-125 release rates are about 100 times higher than the Cs-134 release rates. For both Cs-134 and Sb-125, the highest release rates were observed on condensation plate \#3, which was the first plate in the test to be inserted after the furnace temperature had reached $1400^{\circ} \mathrm{C}$. After peaking at 8.95 hours into the test, both release rates decreased for the duration of the test. The Sb- 125 release rate decreased exponentially from 8.95 hours until the end of the test. Both Cs and Ag release rates decreased sharply (more drastically than $\mathrm{Sb}$ ) from their peaks at 8.95 and $5.2 \mathrm{hrs}$, respectively.

As shown in Figure 23 and Figure 24, there can be point-to-point variations in the Kr-85 activity measured in the FGMS cold trap such that the value for one point may be less than the value in the previous data point. This makes plotting the point-to-point Kr-85 release rate difficult to interpret. Thus, the cumulative Kr-85 release was plotted, and linear fits were used to determine release rates. Figure 23 shows the evolution of Kr-85 throughout the test, and the linear fit gives an average $\mathrm{Kr}-85$ release rate of 2.97E-7 hr-1 over the entire test. In Figure 24, the Kr-85 release-versus-time data are divided into three segments: beginning ( 0 to 16.8 hours), middle (20.8 to 151.8 hrs), and end (155.8 to 306 hrs). Three linear fits are shown in Figure 24 (one for each of the three segments). The $\mathrm{Kr}-85$ release rates are 4.904E-6 hr${ }^{-1}$ from 0 to 16.8 hours, $4.36 \mathrm{E}-7 \mathrm{hr}^{-1}$ from 20.8 to 151.8 hours, and $1.93 \mathrm{E}-7 \mathrm{hr}^{-1}$ from 155 to 306 hours. 
These Kr-85 release rates are greater than those generally observed at $1600^{\circ} \mathrm{C}$ from AGR-1 safety testing (where $\mathrm{Kr}-85$ release rates are on the order of $1 \mathrm{E}-9 \mathrm{hr}^{-1}$ ) and $1700^{\circ} \mathrm{C}$ AGR-1 safety testing where Kr-85 release rates are generally on the order of $1 \mathrm{E}-8 \mathrm{hr}^{-1}$. In the $1800^{\circ} \mathrm{C}$ safety test of AGR-1 Compact 3-2-3, where one or two SiC layer failures occurred, the average $\mathrm{Kr}-85$ release rate was roughly $2 \mathrm{E}-7 \mathrm{hr}^{-1}$, comparable to the average Kr-85 release rate measured for much of this test of AGR-3/4 Compact 10-4. This observed increase in the Kr-85 release rate from AGR-3/4 heating testing suggests that the DTF particles do retain some $\mathrm{Kr}-85$, which is released during post-irradiation heating.

The $\mathrm{Kr}-85$ release rates from the $1400^{\circ} \mathrm{C}$ test of AGR-3/4 Compact $10-4$ can also be compared to those from the $1600^{\circ} \mathrm{C}$ portion of the AGR-3/4 Compact 3-2 test. In Section 3.3.2, it was shown that the total $\mathrm{Kr}-85$ released from Compact 10-4 is very similar to that for Compact 3-2. The Kr-85 release rate for the $1600^{\circ} \mathrm{C}$ test of Compact 3-2 was higher $\left(1.35 \mathrm{E}-5 \mathrm{hr}^{-1}\right)$ for the first 10 hours of that test than the rate for the first 17 hours of the $1400^{\circ} \mathrm{C}$ test of Compact $10-4\left(4.9 \mathrm{E}-6 \mathrm{hr}^{-1}\right)$. However, the two average rates for the remainder (from 17 to 306 hours) of the Compact $10-41400^{\circ} \mathrm{C}$ test $(4.36 \mathrm{E}-7$ and $1.93 \mathrm{E}-7$ $\mathrm{hr}^{-1}$ ) were higher than the two average rates measured between hour 10 and hour 334 of the $1600^{\circ} \mathrm{C}$ portion of the Compact 3-2 test. This may be an indication that more $\mathrm{Kr}-85$ was retained in the Compact 10-4 DTF particles. Compact 3-2 had roughly 10\% higher fluence and 2\% higher TAVA irradiation temperature than Compact 10-4, which could be factors contributing to slightly lower Kr-85 retention in Compact 3-2 DTF particles.

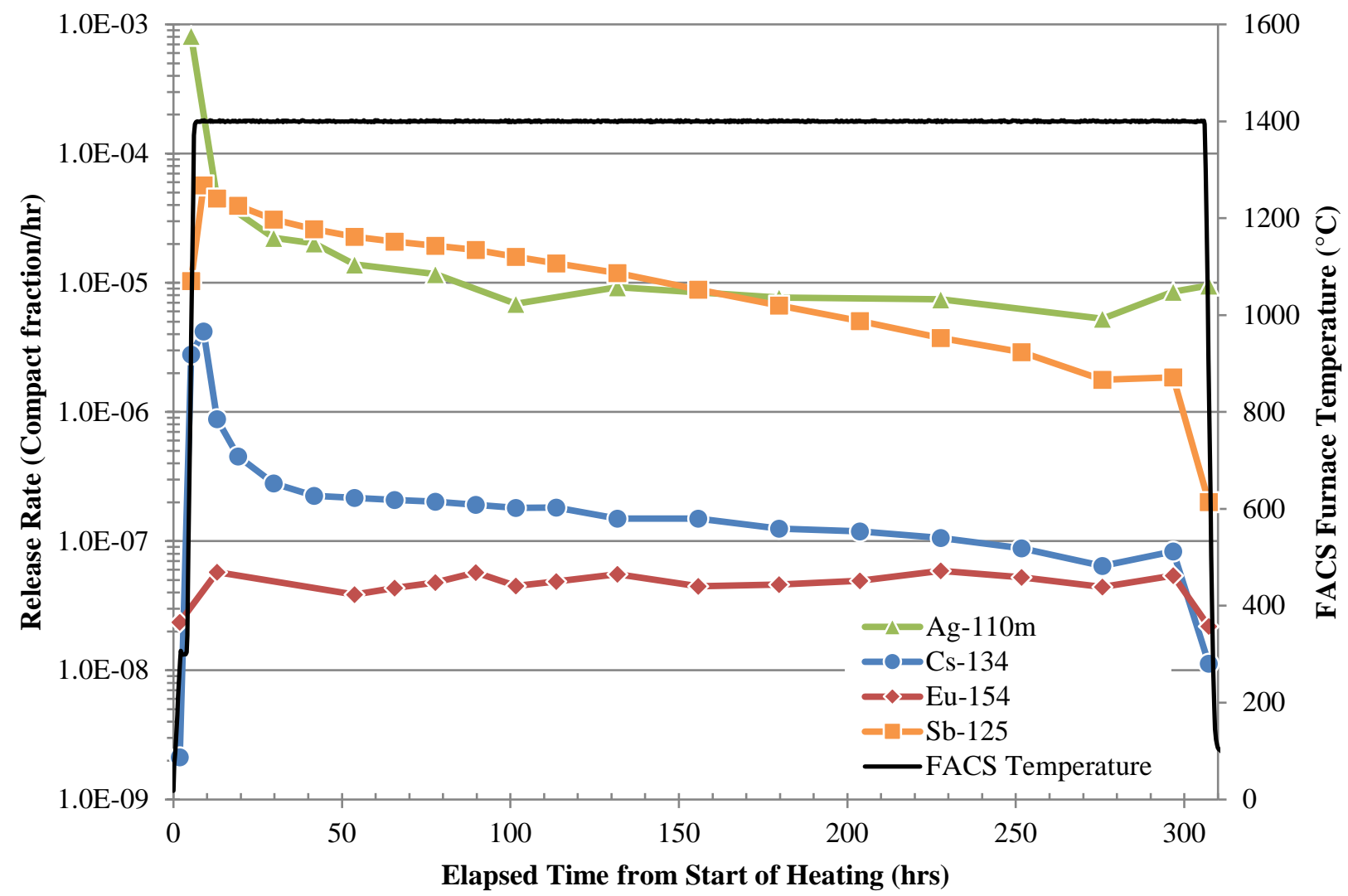

Figure 22. Summary of condensable fission-product release rates from $1400^{\circ} \mathrm{C}$ testing of AGR-3/4 Compact 10-4. 


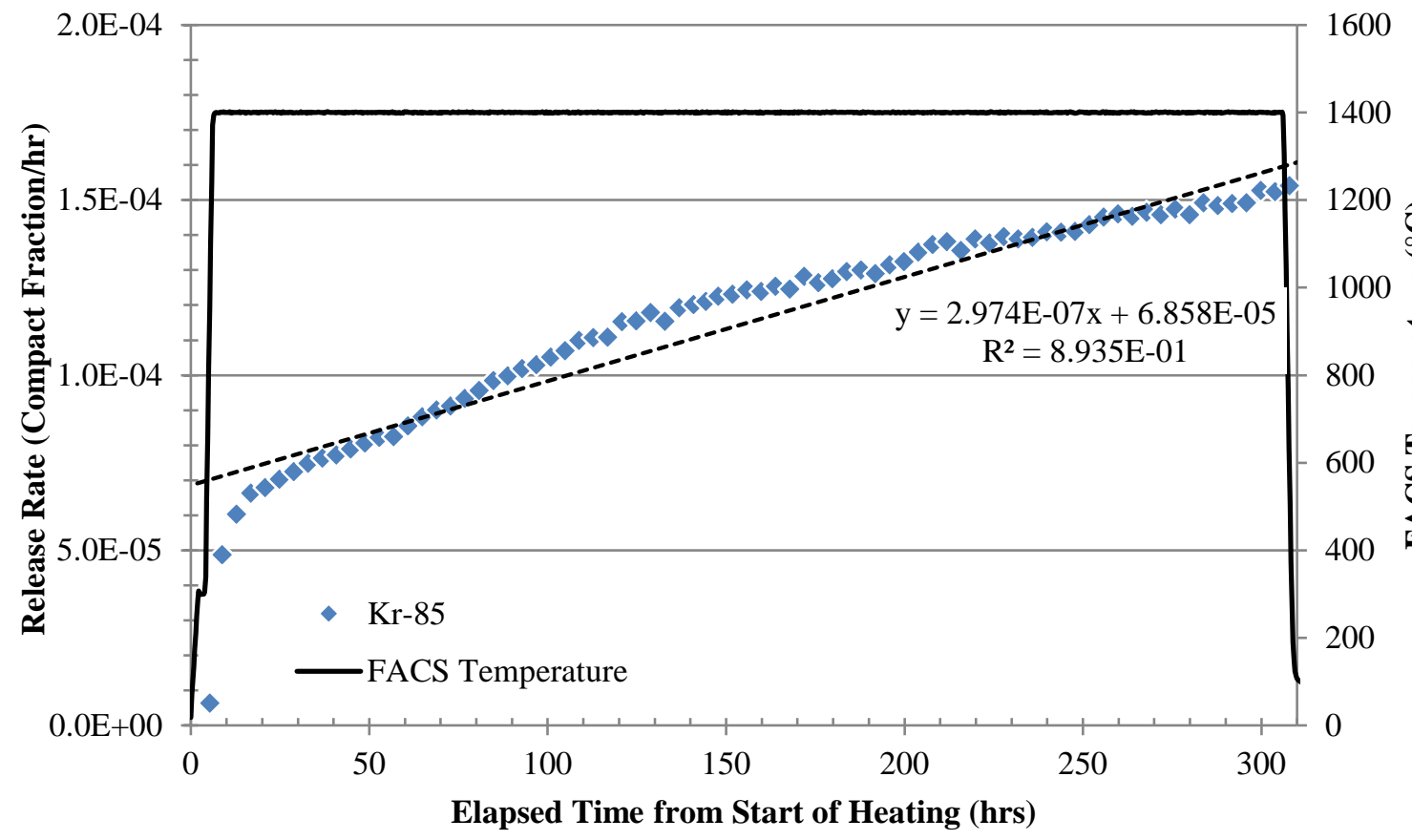

Figure 23. Kr-85 cumulative releases versus time with trend line fit to all Kr-85 data points.

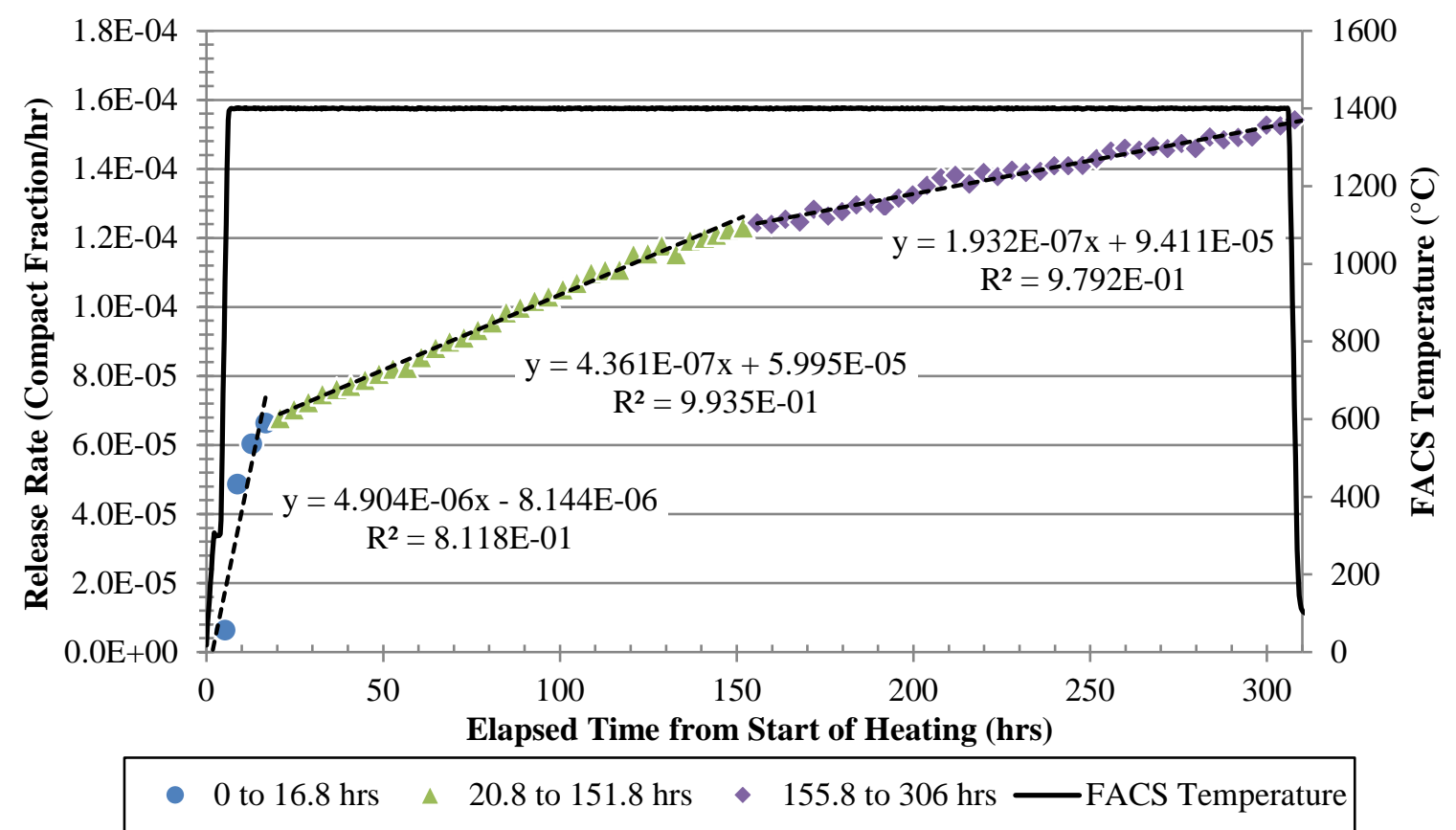

Figure 24. Kr-85 cumulative releases and trend lines giving average release rates over the test. 


\section{SUMMARY AND CONCLUSIONS}

Two AGR-3/4 fuel compacts were heated in the FACS furnace. The test of Compact 3-2 featured a 330 hour hold at $1600^{\circ} \mathrm{C}$ and a 48 hour hold at $1700^{\circ} \mathrm{C}$. Compact $10-4$ was heated for 300 hours at $1400^{\circ} \mathrm{C}$. The results indicated relatively low $\mathrm{Kr}-85$ and cesium release (total release less than a single particle inventory in both tests). This suggests that either the majority of the inventory in the DTF kernels was released during the irradiation, which is likely in the case of Kr-85, or that significant inventory was retained in the DTF kernels during the heating tests, which is a possibility for cesium. Post-test analysis of the compacts may help to better elucidate this behavior. The europium release for Compact 3-2 at $1600 / 1700^{\circ} \mathrm{C}$ was relatively high (released fraction of 7.9E-3, equivalent to the inventory of 15 particles), but notably lower for Compact $10-4$ at $1400^{\circ} \mathrm{C}$ (released fraction of $1.3 \mathrm{E}-5$, equivalent to $2 \%$ of a single particle). The $1600^{\circ} \mathrm{C}$ release was slightly higher than that observed for AGR-1 fuel compacts, and suggests that while the source of release may be similar to that observed for AGR-1 (i.e., slow release of europium present in the compact matrix at the end of irradiation), the matrix inventory was apparently higher in the AGR-3/4 compacts due to the presence of the DTF particles. Additional release from inventory in the DTF kernels during the test could have contributed to the totals. Sb-125 and Ag-110m releases during heating were significant and similar (total release fractions between 1E-3 and 6E-3 for both elements in both tests). In the case of silver, the behavior resembled the release behavior of AGR-1 fuel, and is presumed to be primarily due to inventory in the matrix that was rapidly released upon heatup of the specimens.

A third heating test was performed on three loose, exposed kernels, which were harvested by removing the coatings from intact TRISO particles from AGR-2 Compact 6-4-1. The particles were reirradiated for a total of 32 hours in the NRAD reactor over a period of four days prior to the $1600^{\circ} \mathrm{C}$ heating test. Release of $\mathrm{Kr}-85$ and Xe-133 followed similar general behavior, plateauing after roughly 8 hours of heating (shortly after reaching the target temperature). After 24 total hours of heating, the total $\mathrm{Kr}-85$ release was approximately $2 / 3$ of the predicted inventory in the three kernels. This suggests that 2/3 of the Kr-85 inventory was retained in the kernels both after the TRISO coatings were removed and after the reirradiation had been completed. This also suggests that in the intact particles (prior to cracking to remove the TRISO coatings) $1 / 3$ of the Kr-85 inventory of the particles was located within the particle coatings (most likely the buffer layer) but outside of the kernel itself. Antimony and cesium release from the particles was close to $100 \%$ of the starting inventory (which was also close to the total predicted inventory in the particles). Europium collected on the condensation plates during the test was more gradual, and clearly was influenced by significant retention in the graphite holder that housed the specimens during the heating test, making conclusions about europium release rates from the kernels more difficult to draw. Measurements of the kernels after the test indicate that most ( $>90 \%)$ of the starting inventory was released during the test. Finally, I-131 release was very rapid, similar to the fission gases, with the majority released immediately on reaching $1600^{\circ} \mathrm{C}$ and total release plateauing after about 8 hours. The total fraction of I-131 and Xe-133 released during the test relative to the starting inventory is not yet known, because the starting inventory in the kernels could not be determined by gamma counting. Additional physics calculations to determine the inventory of these isotopes generated during irradiation in NRAD are being performed.

The results presented here are partial and preliminary. Complete analysis of condensation plates (including acid leaching and solution analysis) will provide data on Sr-90. Additional key information needed to interpret the compact heating results will be gathered from the destructive examination of the compacts following the heating tests. This will include radial deconsolidation to remove the outer portions of the compact containing only intact driver particles, and leach-burn-leach analysis of the particles and debris (see Stempien 2017d for a description of the radial deconsolidation method). This will provide information on the fission-product inventory in the compacts outside of the intact SiC layers. Subsequent deconsolidation-leach-burn-leach analysis of the central compact core will dissolve the exposed DTF kernels and may provide the inventory of fission products remaining in the kernels (of 
particular importance for cesium and europium). Interpretation of these results will be simplified if the inventory of fission products in the matrix near the compact center is relatively low compared to the inventory remaining in the kernels. The results will be presented in future reports.

\section{REFERENCES}

Collin, Blaise, P., 2011, “AGR-2 Irradiation Experiment Test Plan,” PLN-3798, Rev. 1, October 2011, Idaho National Laboratory.

Collin, Blaise P., 2014, “AGR-2 Irradiation Test Final As-Run Report,” INL/EXT-14-32277, Rev. 2, August 2014, Idaho National Laboratory.

Collin, Blaise, P., 2015a, “AGR-1 Irradiation Test Final As-Run Report,” INL/EXT-10-18097, Rev. 3, Idaho National Laboratory, January 2015.

Collin, Blaise P., 2015b, “AGR-3/4 Irradiation Test Final As-Run Report,” INL/EXT-15-35550, Rev. 0, Idaho National Laboratory, June 2015.

Collin, B.P., 2015c, “AGR-3/4 Irradiation Experiment Test Plan,” PLN-3867, Rev. 1, Idaho National Laboratory.

Demkowicz, Paul A., et al., 2012, “The Fuel Accident Condition Simulator (FACS) furnace system for high temperature performance testing of VHTR fuel,” Nuclear Engineering and Design 251, 164-172 (2012).

Demkowicz, Paul A., 2013, “AGR-2 Post-Irradiation Examination Plan,” PLN-4616, Rev. 0, December 2013, Idaho National Laboratory.

Demkowicz, P. A., Hunn, J. D., Morris, R. N., van Rooyen, I., Gerczak, T., Harp, J. M. and Ploger, S. A., 2015a, AGR-1 Post-Irradiation Examination Final Report, INL/EXT-15-36407, Idaho National Laboratory.

Demkowicz, P. A., Reber, E.L., Scates, D.M., Scott, L., and Collin, B. P., 2015b "First high temperature safety tests of AGR-1 TRISO fuel with the Fuel Accident Condition Simulator (FACS) furnace,” Journal of Nuclear Materials 464, 320-330,(2015)

Demkowicz, P. A., Ploger, S. A., Winston, P. L., and Harp, J. M., 2016 AGR-1 Compact 1-3-1 PostIrradiation Examination Results, INL/EXT-15-36365, December 2016, Idaho National Laboratory.

Demkowicz, Paul A., 2017, “AGR-3/4 Phase 2 Post-Irradiation Examination Plan,” PLN-5382, Idaho National Laboratory, May 5, 2017.

Hawkes, Grant, 2014, “AGR-2 Daily As-Run Thermal Analyses,” ECAR-2476, Rev. 1, August 2014, Idaho National Laboratory.

Hawkes, Grant L., 2016, “AGR-3/4 Daily As-Run Thermal Analyses,” ECAR-2807, Rev. 1, Idaho National Laboratory, April 21, 2016.

Hunn, J.D., R.A. Lowden, 2007, Data Compilation for AGR-3/4 Driver Fuel Coated Particle Composite LEU03-09T, ORNL/TM-2007/019, Oak Ridge National Laboratory

Hunn, J., M.P. Trammell, F.C. Montgomery, 2011, Data Compilation for AGR-3/4 Designed-to-Fail (DTF) Fuel Compact Lot (LEU03-10TOP2/LEU03-07DTF-OP1)-Z, ORNL/TM-2011/124, Oak Ridge National Laboratory.

Hunn, J. D., Morris, R. N., Baldwin, C. A., Montgomery, F. C., Gerczak, T. J., 2015 PIE on Safety-Tested AGR-1 Compact 4-2-2, ORNL/TM-2015/033, Oak Ridge National Laboratory, March 2015. 
Hunn, J.D., Morris, R. N., Baldwin, C. A., Burns, Z. M., Montgomery, F. C., and Skitt, D. J., 2017, Safety Testing of AGR-2 UCO Compacts 6-4-2 and 2-3-1, ORNL/TM-2017/439, Oak Ridge National Laboratory, August 2017.

INL, 2016, “Technical Program Plan for INL Advanced Reactor Technologies Technology Develop Office/Advanced Gas Reactor Fuel Development and Qualification Program,” PLN-3636, Revision 5, Idaho National Laboratory.

Kercher, A.K., B.C. Jolly, F.C. Montgomery, G.W.C. Silva, and J.D. Hunn, 2011, Data Compilation for AGR-3/4 Designed-to-Fail (DTF) Fuel Particle Batch LEU03-07DTF, ORNL/TM-2011/109, Oak Ridge National Laboratory.

Laug, D., 2017, “ESA-27 NRAD In-core Irradiation of up to 20 TRISO Kernels,” ECAR-2574, February 2017, Idaho National Laboratory.

Scates, D. M., "Release-to-Birth Ratios for AGR-3/4 Operating Cycles 151A through 155B,” ECAR-2457, Rev. 1, June 5, 2015.

Stempien, J. D., 2016, “Test Plan for the Safety Test of Loose Fuel Kernels from AGR-1,” PLN-5118, Rev. 1, Idaho National Laboratory, March 2016.

Stempien, J. D., 2017a, “Test Plan for the Safety Test of Re-irradiated Fuel Particles from AGR-2 Compact 6-4-1,” PLN-5388, Idaho National Laboratory, May 2017.

Stempien, J. D., 2017b, "Test Plan for the Second Reirradiation Heating Test of Fuel Particles from AGR2 Compact 6-4-1,” PLN-5475, Idaho National Laboratory, September 2017.

Stempien, J. D., 2017c, “Test Plan for the $1600^{\circ} \mathrm{C}$ Heating Test of AGR-3/4 Compact 3-2,” PLN-5450, Idaho National Laboratory, August 2017.

Stempien, J. D., 2017d, Radial Deconsolidation and Leach-Burn-Leach of AGR-3/4 Compacts 3-3, 12-1, and 12-3, INL/EXT-17-43182, Idaho National Laboratory, September 2017.

Stempien, J. D., 2017e, “Test Plan for the $1400^{\circ} \mathrm{C}$ Heating Test of AGR-3/4 Compact 10-4,” PLN-5518, Idaho National Laboratory, November 2017.

Sterbentz, James W., 2014, “JMOCUP As-Run Daily Depletion Calculation for the AGR-2 Experiment in ATR B-12 Position,” ECAR-2066, Rev. 2, April 2014, Idaho National Laboratory.

Sterbentz, James W., 2015, “JMOCUP As-Run Daily Physics Depletion Calculation for the AGR-3/4 TRISO Particle Experiment in the ATR Northeast Flux Trap,” ECAR-2753, Rev. 1, Idaho National Laboratory, September 2015. 